\title{
Mixed Channel Service Competition Based on Different Service Pattern in Software-as-a-Service*
}

\author{
Haiqing Hu, Jianyuan Yan
}

Business School, Nankai University, Tianjin, China.

Email: \{huhaiqing_2008,nkyan5559\}@yahoo.com.cn

Received November $20^{\text {th }}, 2011$; revised December $29^{\text {th }}, 2011$; accepted January $11^{\text {th }}, 2012$

\begin{abstract}
Software-as-a-Service (SaaS) realizes the transformation from product to Service through put the software into "clouds". SaaS supply chain is composed of a SaaS ISV (Independent Software Vender) who sells from internet channel and a SaaS dealer. According to different service providers in distribution channel, we sort out three different service patterns, independent service, retailer integrated service and the ISV integrated service. We construct service competition model of three service patterns and study the optimizing decision of the ISV and the dealer. Further more, we explore the impact of customer's service sensibility, channel preference, service cost of the ISV and the dealer, and customer base on service competition. Finally, from supply chain profit maximization perspective, we compared the three service patterns. We found that the advantages and disadvantages of the service pattern depend on the application scene. The paper extent the dual channel research to software service industry and enrich the theory model of dual channel, the result will guide the supply chain member to decide their service pattern.
\end{abstract}

Keywords: Mixed Channel; SaaS; Service; Customer Base

\section{Introduction}

SaaS (Software as a Service: SaaS) is considered a kind of software service which conclude characteristics like [1]: Used with a web browser or other thin client through standard internet protocol, standardized software with no customization, not installment to the customer site, deployment requires no major integration or installation or installation. Customers' payment for use rather than licenses. Multitenant installation for several customers.

According Gartner's forecast, In the enterprise application software market the growth of SaaS is in the most significant, and from 2008 to 2013, the SaaS total income growth rate is $19.4 \%$ in global market, three times compared with the annual rate $[2,3]$. SaaS has been paid more attention in academia and the practice.

But Wu (2011) thinked SaaS is not popular in software market [4], from a perspective of SaaS service provider, SaaS promotion are still the most urgent and the most important issue in current. From a marketing perspective, the channel plays an important role in the promotion of products or services. The channel of SaaS supply is developing from direct channel to dual channel composed of internet direct distribution channel and traditional distri-

${ }^{*}$ Funded by the NSFC (71172072): SaaS-based IT Service Supply Chain Contracts and Incentive Mechanism Research. bution channel, like Weiku, Youshang, Babaike, and Salesforce.

At present most of SaaS research are qualitative, say, Benlian [5], Benlian, et al. [6], Mietzner, et al. [7], only a very small part research is quantitative. Fan et al. researched the competition between SaaS ISV and traditional ISV in short-term and long-term, they found that SaaS ISV will face high introduction cost in short-term, but in long time it will be help to increase customer base [8]. Cheng et al. [9] puts forward three coordination strategies for SaaS supply chain composed of a ISV supplier and a dealer, but this study is based on a single channel hypothesis.

Previous literature of dual distribution channel focused primarily on the physical product, and the model cannot response service characteristics. So some scholars researched the special industry optimization decision, such as Bhattacharjee researched the music pricing mechanism in traditional channel and network channel [10], Hua researched sales pattern in dual channels of books from the perspective of the book vendor [11], Khouja researched decision optimization of dual channel of empirical goods which can be sold in either physical form or digital form [12], Hu et al. researched decision optimization of service supply chain [13]. E-books and music is consumer goods, and SaaS is industrial goods, and its sales in a big difference, such as SaaS service decision replaced price decisions, 
service have the cost. The previous study found that there are different results as long as the research background or research object is different. Therefore, it is necessary to study the SaaS dual channel decision optimization.

Based on SaaS characteristics, separate its human service from application service, we sort out three different service patterns, independent service, retailer integrated service and the ISV integrated service. We construct service competition model of independent service pattern and study the optimizing decision of the ISV and the dealer. Further more, we explore the impact of customer's service sensibility, channel preference, service cost of the ISV and the dealer, and customer base on service competition. Finally, from supply chain profit maximization perspective, we compared the three service patterns. The paper extent the dual channel research to software service industry and enrich the theory model of dual channel, the result will guide the supply chain member to decide their service pattern.

\section{Literature Review}

The channel structure will affect channel members' decision. The dual channel price competition is most popular, so prices decision and pricing mechanism choice is the main research problems. Chiang et al. (2003) studied dual channel pricing under stackelberg game and the assumption consumer channel preferences is constant without influence from other channels decision variables [14]. Other scholars study dual channel pricing extent this paper to consider consumer preference [15-17], information sharing $[18,19]$, market structure [20], network externalities and free rider problem [21].

Service is non-price factor which positive impact demand [22-24]; the empirical research found that the service quality [25-26] and transaction cost [27] are main factors to impact consumers to accept direct channel, the impact of the service quality surpass the product price [28]. Rajiv Dhawan thinked the excellence operation of service supply chain based on knowledge should depend on service quality [29], R. Emst thinked the software demand is quite sensitive to distributors service level [30], and Philip also thinked the high technology and the high complex operation of products or services required higher service level [31].

Service competition is different from price competition, Service competition is imperceptibility and service has costs. The cost curve will impact the competition, so the service competition imperceptibility and the cost curve make service competition different with price competition. The previous dual channel studies consider service were also based on price competition and assuming that dealer charge of service, the research purpose is how to motivate dealer to improve customer service level, such as Li study supply chain member's competition from the differences of service level and e-commerce implementing degree in- cluding strong and weak retailers [32], Liu study how to motivate retailers to provide high quality service level under two supply chain competition, based on the assumption that service level will affect consumer satisfaction and the demand, using the principal-agent theory, under the information asymmetry and symmetry situation [33]. This paper on the guide of dual channel price decisions research results, based on SaaS characteristics, study channel member's service level optimization decision of dual channel under service competition.

\section{Service Pattern and Basic Model}

\subsection{SaaS Dual Channel Service Pattern}

SaaS service including product services and application service, product services include maintenance and upgrade charged with ISV. Application service is application implementation service which can help customer to use SaaS, such as customer training, which can be charged with ISV or dealer or both. If ISV is responsible for all application service from both channels, we call it ISV integrated service pattern, if dealer is responsible for all application service from both channels, we call it dealer service integrated pattern, if they are responsible for their respective independent channels, we call it independent service pattern.

\subsection{Assumption}

Market structure: although there are many SaaS ISV at present, but their service distinguish higher, that is, each ISV is monopoly for their service, so we assumption the SaaS market is monopoly. Supply chain is composed by a SaaS ISV and a dealer, they play stackelberg game.

Channel preferences: each channel has its certain cost structure and capacity, limiting depth and breadth of their products and services. Direct channel limits customer's service due to its low customer contacts. Multi-channel can meet the different needs of the market, but the customer ownership will affect channel member's enthusiasm [34]. In model construction consumers are often not only heterogeneous, but also existing channels preference. Khouja considered the retail-captive consumers may be for the following reasons and refuse to use network channel [35]: loyalty to retailers [36], no access, concerning the privacy and security problems, can't experience or feelings products [37], return difficult [38], or worry about financial security [39]. In the interview the manager of Xtools, we got that "through the dealer we can contact with offline customers", they think, customers can be divided into two kinds, one is high internet dependency, another is low internet dependency. The former more inclined to buy services through direct channel, while the latter tend to purchase service through the agency channel. So from the existing academic research and enterprise practice, it is assumed that SaaS customer preferences existing channels. 
Customer installed base: an important condition of dealer selection is the amount of customer installed base, the customer installed base directly affect the adoption of SaaS customer volume, so that the dealer's existing customer installation will affect SaaS demand.

Service function: service industry production function characteristics discussion comes after Fuchs (1968) [40], service process is different from manufacturing in the four aspects: 1) lack of visible output; 2) no inventory; 3) production and consumption simultaneously; 4) producers and consumers cooperation to create services; 5) customer participation, customer orientation, and the difficulty of remote services [41]. Software service cost including implementation and maintenance cost [42]. SaaS service is different from the general physical products and electronic products, because service importance of these products is relatively low compared with SaaS. Service is an integral part of SaaS, the marginal cost of software can be ignored, but the marginal cost of service could not be ignored. SaaS still need the promotion service to promote sales, so SaaS services include SaaS implement related services and promotion related service, the former service cost is mainly includes pre-sale consultation, the user training, which includes service response speed, service response range, such as $7 \times 24$ hours online service, is similar with the traditional products services. The former service costs is sales related, and the latter's service activities is fixed, mainly depends on the human and the equipment investment, this cost is depended on service level. Most scholars constructed service cost function as $t$ convex function of service level [43-46]. $C_{i}\left(s_{i}\right)=\lambda_{i} \frac{s_{i}^{2}}{2}, s_{i}$ is service level, $\lambda_{i}$ is constant. Feng (2009) also applied this function as a service cost function when he study digital products' distribution stratgies. According to the practice and existing research results, we assume SaaS service function as $C_{i}\left(s_{i}\right)=\beta_{i} \cdot D_{i}+\lambda_{i} \cdot \frac{s_{i}^{2}}{2}$ (See Table $\mathbf{1}$ ).

This paper all parameters are nonnegative, $\theta \in[0,1]$ $p>\beta_{1}, \quad p>\beta_{2}, \quad w \in\left[0, p-\beta_{2}\right]$.

SaaS dealer's customer base is $\delta a$, the market capacity of ISV direct channel is $\theta a$, the market capacity of dealer channel is $(1-\theta+\delta) a$. Their demand functions are as follows:

$$
\begin{aligned}
& D_{1}=\theta a+f s_{1}+\gamma\left(s_{1}-s_{2}\right) \\
& D_{2}=(1-\theta+\delta) a+f s_{2}+\gamma\left(s_{2}-s_{1}\right)
\end{aligned}
$$

Because demand is nonnegative, we get

$$
\begin{aligned}
& s_{1} \in\left[\frac{\gamma s_{2}-\theta a}{f+\gamma}, \frac{(1-\theta+\delta) a+(f+\gamma) s_{2}}{\gamma}\right] ; \\
& s_{2} \in\left[\operatorname{Max}\left\{0, \frac{a(\gamma \theta-(f+\gamma)(1-\theta+\delta))}{f(f+2 \gamma)}\right\},+\infty\right) .
\end{aligned}
$$

\begin{tabular}{|c|c|}
\hline symbol & Meaning \\
\hline$a$ & ISV's market capacity \\
\hline$\delta$ & ratio of dealer's customer base to ISV's market capacity \\
\hline$f$ & Absolute service level parameter of demand \\
\hline$\gamma$ & relative service level parameter of demand \\
\hline$\theta$ & Internet direct channel preference \\
\hline$D_{i}$ & Channel demand, $i=1$ direct channel, $i=2$ dealer channel \\
\hline$s_{i}$ & Service level, $i=1$ direct channel, $i=2$ dealer channel \\
\hline$\beta_{i}$ & $\begin{array}{l}\text { Unit service cost, } i=1 \text { direct channel, } \\
i=2 \text { dealer channel }\end{array}$ \\
\hline$\lambda_{i}$ & $\begin{array}{l}\text { Parameter of service level cost, } \\
i=1 \text { direct channel, } i=2 \text { dealer channel }\end{array}$ \\
\hline$\pi_{i}$ & profit, $i=1$ direct channel, $i=2$ dealer channel \\
\hline$\pi$ & Supply chain profit \\
\hline$p$ & Unit price \\
\hline$w$ & Unit wholesale price \\
\hline
\end{tabular}

Table 1 Symbol declaration.

The profit functions of ISV and dealer aer as follows:

$$
\begin{aligned}
& \pi_{1}=\left(p-\beta_{1}\right) D_{1}+w D_{2}-\lambda_{1} s_{1}^{2} / 2 \\
& \pi_{2}=\left(p-w-\beta_{2}\right) D_{2}-\lambda_{2} s_{2}^{2} / 2
\end{aligned}
$$

Properties of the profit function are as follows:

1) Each of profit function is convex;

$$
\begin{aligned}
& \text { 2) } \frac{\frac{\lambda_{1} s_{1}^{2}}{2}-\left(p-\beta_{1}\right) D_{1}}{D_{2}} \leq w \leq \frac{\left(p-\beta_{2}\right) D_{2}-\frac{\lambda_{2} s_{2}^{2}}{2}}{D_{2}} \\
& \text { 3) } \frac{\lambda_{1} s_{1}^{2}+\lambda_{2} s_{2}^{2}}{2} \leq p\left(D_{1}+D_{2}\right)-\left(\beta_{1} D_{1}+\beta_{2} D_{2}\right)
\end{aligned}
$$

The total supply chain profit function is as follow:

$$
\pi=\left(p-\beta_{1}\right) D_{1}+\left(p-\beta_{2}\right) D_{2}-\lambda_{2} s_{2}^{2} / 2-\lambda_{1} s_{1}^{2} / 2
$$

\section{Decision}

\subsection{Centralized Decision}

The decision objective is to maximize the supply chain profit in centralized decision. From that we get the optimal service level and the optimal profit, which will become the benchmark of other decision. 


$$
\begin{aligned}
s_{1}^{*}= & \frac{f\left(p-\beta_{1}\right)-\gamma\left(\beta_{1}-\beta_{2}\right)}{\lambda_{1}}, \\
s_{2}^{*}= & \frac{f\left(p-\beta_{2}\right)-\gamma\left(\beta_{2}-\beta_{1}\right)}{\lambda_{2}} \\
\pi^{*}= & \frac{1}{2 \lambda_{1} \lambda_{2}}\left(\left(f p-(f+\gamma) \beta_{1}+\gamma \beta_{2}\right)^{2} \lambda_{2}\right. \\
& +\lambda_{1}\left(\gamma^{2} \beta_{1}^{2}+(f+\gamma)^{2} \beta_{2}^{2}+p\left(f^{2} p+2 a(1+\delta) \lambda_{2}\right)\right. \\
& -2 \beta_{2}\left(f p(f+\gamma)+a(1+\delta-\theta) \lambda_{2}\right) \\
& \left.\left.+2 \beta_{1}\left(f p \gamma-\gamma(f+\gamma) \beta_{2}-a \theta \lambda_{2}\right)\right)\right)
\end{aligned}
$$

\subsection{Decentralized Decision}

When ISV and dealer make their decision independently and they are responsible for their customer service independently, their decision relationship and decision order are as shown in Figure 1. First of all, ISV decide its' service level and wholesale price, and then the dealer decide its' service level.

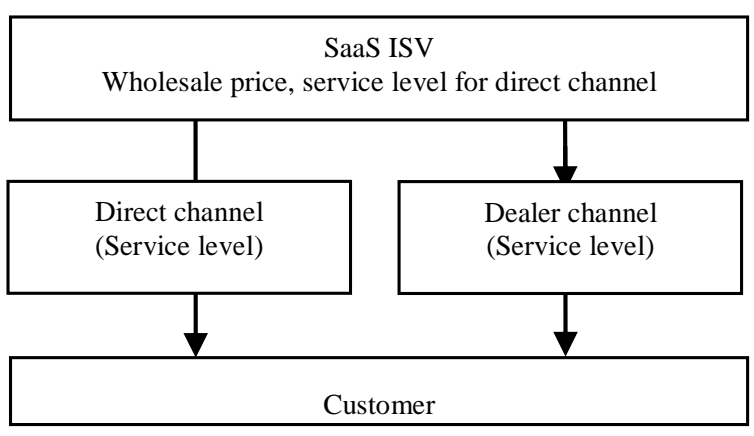

Figure 1. The decision relationship of ISV and dealer.

\subsubsection{Stackelberg Game}

Proposition 1: the dealer's optimal response function is $s_{2}(w)=\frac{(f+\gamma)\left(p-w-\beta_{2}\right)}{\lambda_{2}}$, which only rely on ISV's wholesale price, foreign to ISV's service level.

Proposition 2: when $f>\left(\sqrt{\frac{\lambda_{2}}{2 \lambda_{1}}}-1\right) \gamma$, ISV's optimal decision is

$$
\begin{gathered}
w^{*}=\frac{-\gamma(f+\gamma)\left(p-\beta_{1}\right) \lambda_{2}+\lambda_{1}\left((f+\gamma)\left(p(f+2 \gamma)-\gamma \beta_{1}-(f+\gamma) \beta_{2}\right)+a(1-\theta+\delta) \lambda_{2}\right)}{2(f+\gamma)^{2} \lambda_{1}-\gamma^{2} \lambda_{2}}, \\
s_{1}^{*}=\frac{(f+\gamma)\left(f p(2 f+3 \gamma)-\left(2 f^{2}+4 f \gamma+\gamma^{2}\right) \beta_{1}+\gamma(f+\gamma) \beta_{2}\right)+a \gamma(-1+\theta-\delta) \lambda_{2}}{2(f+\gamma)^{2} \lambda_{1}-\gamma^{2} \lambda_{2}},
\end{gathered}
$$

so the dealer's optimal decision is

$$
s_{2}^{*}=\frac{(f+\gamma)\left(-(f+\gamma)\left(f p+\gamma \beta_{1}-(f+\gamma) \beta_{2}\right) \lambda_{1}+\left(\gamma(f+\gamma) \beta_{1}-\gamma\left(f p+\gamma \beta_{2}\right)+a(1-\theta+\delta) \lambda_{1}\right) \lambda_{2}\right)}{\lambda_{2}\left(-2(f+\gamma)^{2} \lambda_{1}+\gamma^{2} \lambda_{2}\right)} .
$$

\subsubsection{Comparative Statistic Analysis}

4.2.2.1. Customer Base Impact on Optimal Profit of ISV, Dealer and Supply Chain

1) Customer base impact on optimal profit of the ISV.

When $f>\gamma\left(\sqrt{\lambda_{2} / 2 \lambda_{1}}-1\right)$,

$$
\delta_{1 \pi}^{\prime \prime}=\frac{\gamma(f+\gamma)\left(p-\beta_{1}\right) \lambda_{2}+\lambda_{1}\left((f+\gamma)\left(-p(f+2 \gamma)+r \beta_{1}+(f+\gamma) \beta_{2}+a(-1+\theta) \lambda_{2}\right)\right.}{a \lambda_{1} \lambda_{2}} .
$$

When $\delta>\delta_{1 \pi}^{\prime \prime}$, ISV's optimal profit is increasing with $\delta$. When $\delta<\delta_{1 \pi}^{\prime \prime}$, ISV's optimal profit is decreasing with $\delta$.

The market capacity will increase because of dealer's customer base after ISV introduces the dealer to sale SaaS service. When the customer base is low, ISV increase market is less than the dealer cut from ISV original market, so ISV optimal profit decrease with customer base. When the costumer base is high, ISV increase market will be more than the dealer cut from ISV original market, and ISV also $\frac{\partial^{2} \pi_{1}^{*}}{\partial \delta^{2}}=\frac{a^{2} \lambda_{1} \lambda_{2}}{2(f+\gamma)^{2} \lambda_{1}-\gamma^{2} \lambda_{2}}>0$,

so ISV's optimal profit is a convex function of customer base. Make the first order derivatives function to zero, we get share a part of the dealer's profit through wholesale price, so ISV optimal profit increase with customer base.

2) Customer base impact on optimal profit of the dealer.

Because $\frac{\partial^{2} \pi_{2}^{*}}{\partial \delta^{2}}=-\frac{3 a^{2}(f+\gamma)^{2} \lambda_{1}^{2} \lambda_{2}}{\left(-2(f+\gamma)^{2} \lambda_{1}+\gamma^{2} \lambda_{2}\right)^{2}}<0$, the

dealer's optimal profit is a concave function of customer base. Make the first order derivatives function to zero, we get 


$$
\delta_{2 \pi}^{\prime \prime}=\frac{\gamma\left(f p(3 f+4 \gamma)-\left(3 f^{2}+6 f \gamma+2 \gamma^{2}\right) \beta_{1}+2 \gamma(f+\gamma) \beta_{2}\right) \lambda_{2}+(f+\gamma) \lambda_{1}\left((f+\gamma)\left(p f+r \beta_{1}-(f+\gamma) \beta_{2}\right)+3 a(-1+\theta) \lambda_{2}\right)}{3 a(f+\gamma) \lambda_{1} \lambda_{2}} .
$$

When $\delta<\delta_{2 \pi}^{\prime \prime}$, the Dealer's optimal profit is increasing with $\delta$. When $\delta>\delta_{2 \pi}^{\prime \prime}$, the Dealer's optimal profit is decreasing with $\delta$.

Although the customer base can increase the SaaS dealer's customer volume, the wholesale price is increasing function of customer base. When customer base is low, with the increase of customer base, SaaS service provider wholesale prices will also increase. The gains from the customer base increase is lower than the loss from the transfer payment to SaaS service provider, so SaaS dealer's profits will be decreasing with the customer base. When customer base is high, The gains from the customer base increase is higher than the loss from the transfer payment to SaaS service provider, so SaaS dealer's profits will be increasing with the customer base.

3) Customer base impact on optimal profit of the supply chain.

$$
\text { Because } \frac{\partial^{2} \pi^{*}}{\partial \delta^{2}}=-\frac{a^{2} \lambda_{1} \lambda_{2}\left((f+\gamma)^{2} \lambda_{1}+\gamma^{2} \lambda_{2}\right)}{\left(-2(f+\gamma)^{2} \lambda_{1}+\gamma^{2} \lambda_{2}\right)^{2}}<0 \text {, the }
$$

optimal profit of supply chain is a concave function of customer base. Make the first order derivatives function to zero, we get

$$
\begin{aligned}
\delta_{\pi}^{\prime \prime}= & \frac{1}{a \lambda_{1} \lambda_{2}\left((f+\gamma)^{2} \lambda_{1}+\gamma^{2} \lambda_{2}\right)^{2}}\left(\gamma^{3}(f+\gamma)\left(p-\beta_{1}\right) \lambda_{2}^{2}+(f+\gamma)^{2} \lambda_{1}^{2}\left((f+\gamma)\left(3 f p+4 p \gamma-\gamma \beta_{1}-3(f+\gamma) \beta_{2}\right)\right.\right. \\
& \left.\left.\left.+a(-1+\theta) \lambda_{2}\right)+\gamma \lambda_{1} \lambda_{2}\left((f+\gamma)\left(p\left(f^{2}-f \gamma-4 \gamma^{2}\right)+\left(-f^{2}-2 f \gamma+\gamma^{2}\right) \beta_{1}\right)+3 \gamma(f+\gamma) \beta_{2}\right)+a \gamma(-1+\theta) \lambda_{2}\right)\right)
\end{aligned}
$$

When $\delta<\delta_{\pi}^{\prime \prime}$, the supply chain optimal profit is increasing with $\delta$. When $\delta>\delta_{\pi}^{\prime \prime}$, the supply chain optimal profit is decreasing with $\delta$.

Because customer base impact the SaaS dealer directly, and impact the SaaS service provider indirectly, and the supply chain optimal profit of SaaS mixed channel is aggregation of the optimal profit of the SaaS service proveder's and the dealer's under decentralized decision, so impact of customer base on the optimal profit of supply chain is same as the impact on the dealer's. In the other words, it manifest that the influence degree of customer base to the dealer is more than to the ISV (See

\section{Figure 2).}

\subsubsection{Customer Preference Impact on the Optimal} Profit of ISV, Dealer, and Supply Chain

1) Customer preference impact on the optimal profit of ISV.

When $f>\gamma\left(\sqrt{\lambda_{2} / 2 \lambda_{1}}-1\right)$,

$\frac{\partial^{2} \pi_{1}^{*}}{\partial \theta^{2}}=\frac{a^{2} \lambda_{1} \lambda_{2}}{2(f+\gamma)^{2} \lambda_{1}-\gamma^{2} \lambda_{2}}>0$, so ISV's optimal profit

is a convex function of customer preference. Make the first order derivatives function to zero, we get

$$
\theta_{1 \pi}^{\prime \prime}=\frac{f \gamma\left(-p+\beta_{1}\right) \lambda_{2}+\lambda_{1}\left(-(f+\gamma)\left(f p-(2 f+\gamma) \beta_{1}+(f+\gamma) \beta_{2}\right)+a(1-\delta) \lambda_{2}\right)}{a \lambda_{1} \lambda_{2}}
$$

when $\theta>\theta_{1 \pi}^{\prime \prime}$, ISV's optimal profit is increasing with $\theta$. when $\theta<\theta_{1 \pi}^{\prime \prime}$, ISV's optimal profit is decreasing with $\theta$. Intuitively, when the customer preference is zero, ISV only share the benefits of the dealer by the wholesale price. The whole sale price is a decreasing function of customer preference, and the ISV's service level is a increasing function of customer preference. With the increase of customer preferences, although the ISV's direct channel sales income is increasing, when the increase profit of sales income can't offset the service cost increase and the wholesale price decline, the optimal profits of the SaaS service provider will be decreasing with customer preference increasing. But the increase profit of sales income is more than the service cost increase and the wholesale price decline, the optimal profits of the ISV will be increasing with customer preference increasing.

2) Customer preference impact on the optimal profit of the dealer.

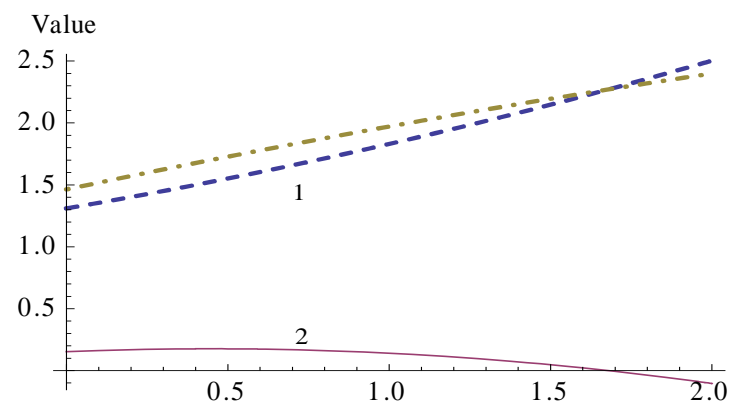

Figure 2. Customer base impacts on optimal profit of ISV, dealer and supply chain. 


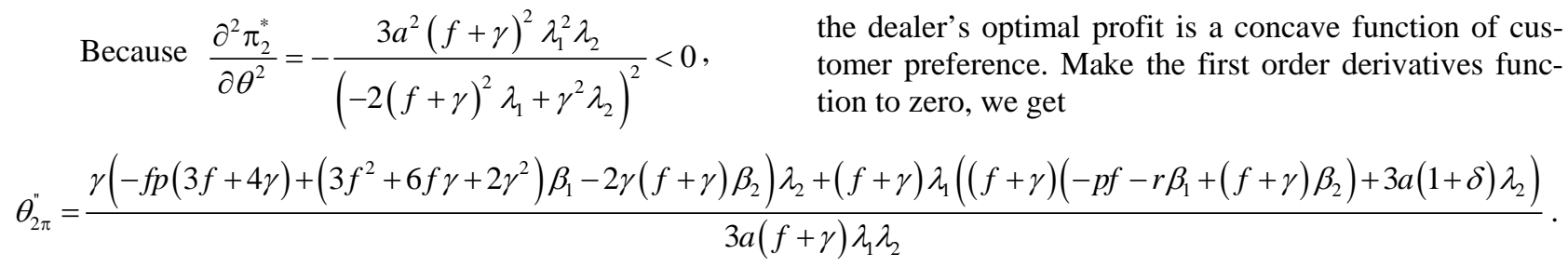

When $\theta<\theta_{2 \pi}^{\prime \prime}$, the Dealer's optimal profit is increasing with $\theta$. When $\theta>\theta_{2 \pi}^{\prime \prime}$, the Dealer's optimal profit is decreasing with $\theta$.

The whole sale price is a decreasing function of customer preference, and the dealer's service level is an increasing function of customer preference. When customer preference is zero, the dealer has all the customers. The dealer give ISV high transfer payment. Along with the increase of customer preferences, as long as the cost saveing from transfer payments is higher than sales income loss and service cost, the dealer's optimal profit will be increasing with the customer preference. When the cost saveing from transfer payments is lower than sales income loss and service cost, the dealer's optimal profit will be decreasing with the customer preferences.

3) Customer preference impact on the optimal profit of supply chain

$$
\text { Because } \frac{\partial^{2} \pi^{*}}{\partial \theta^{2}}=-\frac{a^{2} \lambda_{1} \lambda_{2}\left((f+\gamma)^{2} \lambda_{1}+\gamma^{2} \lambda_{2}\right)}{\left(-2(f+\gamma)^{2} \lambda_{1}+\gamma^{2} \lambda_{2}\right)^{2}}<0,
$$

the optimal profit of supply chain is a concave function of customer preference. Make the first order derivatives function to zero, we get

$$
\begin{aligned}
\theta_{\pi}^{\prime \prime}= & (1+\delta)+\frac{f \gamma\left(-p+\beta_{1}\right)}{a \lambda_{1}} \\
& +\frac{(f+\gamma)\left(f p-(4 f+3 \gamma) \beta_{1}+3(f+\gamma) \beta_{2}\right)}{a \lambda_{2}} \\
& -\frac{3 \gamma^{2}(f+\gamma)\left(f p-(3 f+2 \gamma) \beta_{1}+2(f+\gamma) \beta_{2}\right)}{a(f+\gamma)^{2} \lambda_{1}+a \gamma^{2} \lambda_{2}}
\end{aligned}
$$

when $\theta<\theta_{\pi}^{\prime \prime}$, the supply chain optimal profit is increasing with $\theta$. When $\theta>\theta_{\pi}^{\prime \prime}$, the Dealer's optimal profit is decreasing with $\theta$ (See Figure 3 ).

The customer preference reflects the SaaS market characteristics, customer preferences higher or lower is representative of SaaS market concentration. The important goal of setting up a mixed channel is to expand the market coverage, and cover all kinds of customers. From the above analysis result, we can see that the optimal profit of supply chain is a convex function of the customer preference, and the impact of market characteristics on supply chain. From the same impact of customer preference on supply chain and on the dealer, we can see that the influence degree of customer preference to the dealer is higher than to the ISV.

\section{Compared Decentralized Decision with Centralized Decision}

\subsection{Supply Chain Optimal Profit Comparison}

Because of the complexity to judge profits difference, so choose numerical simulation to illustrate the profit difference between centralized decision and decentralized decision. According to the model hypothesizes, we set $\left\{f, \gamma, \lambda_{1}, \lambda_{2}, p, \beta_{1}, \beta_{2}, \delta, \theta, a\right\}=\left\{0.2 k, 0.2, m \lambda_{2}, 0.3,0.8, n \beta_{2}\right.$, $\delta, \theta, 1\}$ as the value of the parameter.

$k=\frac{f}{\gamma}, m=\frac{\lambda_{1}}{\lambda_{2}}, n=\frac{\beta_{1}}{\beta_{2}}$.

1) The impact from the ratio of absolute service level parameter to relative service level parameter.

$k$ is the ratio of absolute service level parameter to relative service level parameter, which reflect the relative size of the absolute service level parameter and the relative service level parameter. If $k>1$, the influence to the demand of service level is greater than of service level differences. If $k<1$, the influence to the demand of service level differences is greater than of service level. Figure 4 illustrates the impact of $k$ on supply chain optimal profit difference between centralized decision and decentralized decision. $m, n$ indicate service cost difference between ISV and its dealer. If $m>1, n>1$, it means that ISV service cost is higher than its dealer, otherwise, ISV service cost is lower than its dealer.

As shown in Figure 4, we can see that the optimal profit of supply chain in centralized decision is higher than in decentralized decision, and when $k$ is higher than a particular value, the supply chain optimal profit under decentralized decision is more closely to centralized decision.

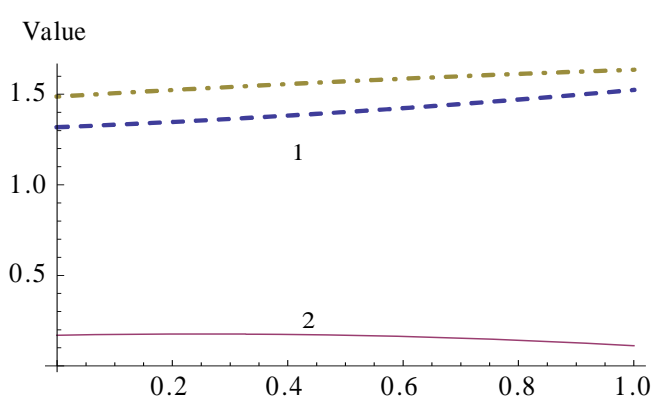

Figure 3. Customer preference impact on the optimal profit of ISV, dealer, and supply chain. 


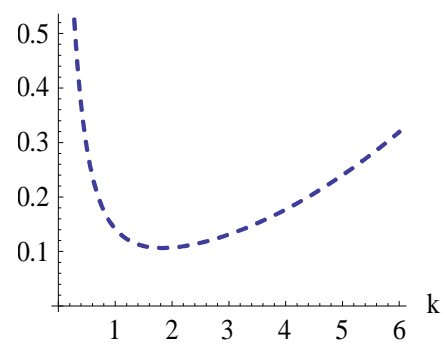

$\{\mathrm{m}, \mathrm{n}, \delta, \theta\}=\{1.2,1.2,0.5,0.5\}$

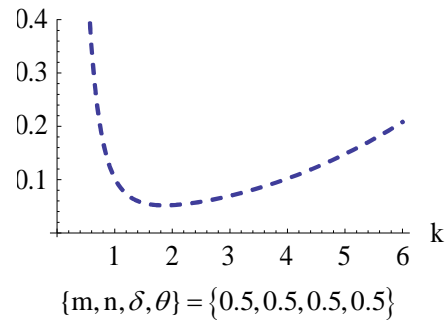

Figure 4. The impact of the ratio of absolute service level parameter to relative service level parameter.

The ratio of the absolute service level parameter to the relative service level represents the strength of mixed channel competition. When the ratio is less than or equal to 1 , the smaller the ratio, the more intense competition between the ISV and the dealer. From the influence of the ratio on the supply chain optimal profit difference between centralized decision and decentralized decision, the smaller the ration, the bigger profit difference. Observe different service cost of the ISV and the dealer, we find that when the ISV service cost is lower, the optimal profits difference between centralized decision and decentralized decision is smaller. Through the numerical simulation we can two points of enlightenment, the first one is that if the customer sensitivity to the service level difference of the mixed channel is higher than to the service level of their preference channel, the decentralized decision is not suitable for the mixed channel, and the ISV should build its own channel or integrate the dealer's channel in order for cen- tralized decision. The second one is that if the ISV service cost is lower than the dealer, the supply chain optimal profit in decentralized decision is more closely to the optimal profit in centralized decision.

2) The impact from customer reference and customer base.

$$
\text { Because } \frac{\partial^{2} \Delta \pi}{\partial \theta^{2}}=\frac{a^{2} \lambda_{1} \lambda_{2}\left((f+\gamma)^{2} \lambda_{1}+\gamma^{2} \lambda_{2}\right)}{\left(-2(f+\gamma)^{2} \lambda_{1}+\gamma^{2} \lambda_{2}\right)^{2}}>0,
$$

the optimal profit difference of supply chain between centralized decision and decentralized decision is a convex function of customer preference. There is no resolution when the first order derivatives function is zero. It illustrate that no matter how much of the customer preference is, the supply chain optimal profit in centralized decision is more than in decentralized decision.

$$
\text { Because } \frac{\partial^{2} \Delta \pi}{\partial \delta^{2}}=\frac{a^{2} \lambda_{1} \lambda_{2}\left((f+\gamma)^{2} \lambda_{1}+\gamma^{2} \lambda_{2}\right)}{\left(-2(f+\gamma)^{2} \lambda_{1}+\gamma^{2} \lambda_{2}\right)^{2}}>0,
$$

the optimal profit difference of supply chain between centralized decision and decentralized decision is a convex function of customer base. There is no resolution when the first order derivatives function is zero. It illustrate that No matter how much of the customer base is, the supply chain optimal profit in centralized decision is more than in decentralized decision.

From the impact of customer preference and customer base on supply chain profit difference between two decisions, we can see that no matter how much the two parameters are, it can not change the conclusion that the supply chain optimal profit in centralized decision is more than in decentralized decision.

\subsection{Service Level Comparison and Analysis}

The optimal service level difference of ISV in centralized decision and in decentralized decision is

$$
\Delta s_{1}=\frac{-\gamma(f+\gamma)\left(f p+\gamma \beta_{1}-(f+\gamma) \beta_{2}\right) \lambda_{1}+\gamma\left(\gamma(f+\gamma) \beta_{1}-\gamma\left(f p+\gamma \beta_{2}\right)+a(1+\delta-\theta) \lambda_{1}\right) \lambda_{2}}{\lambda_{1}\left(2(f+\gamma)^{2} \lambda_{1}-\gamma^{2} \lambda_{2}\right)} .
$$

If $\lambda_{2}>\lambda_{1}$ and

$$
\beta_{1}>\frac{-\gamma\left(f p+\gamma \beta_{2}\right) \lambda_{2}+\lambda_{1}\left(-f p(f+\gamma)+(f+\gamma)^{2} \beta_{2}+a(1+\delta-\theta) \lambda_{2}\right)}{\gamma(f+\gamma)\left(\lambda_{1}-\lambda_{2}\right)},
$$

the optimal service level of ISV in centralized decision is higher than in decentralized decision. If $\lambda_{2}<\lambda_{1}$ and

$$
\beta_{1}<\frac{-\gamma\left(f p+\gamma \beta_{2}\right) \lambda_{2}+\lambda_{1}\left(-f p(f+\gamma)+(f+\gamma)^{2} \beta_{2}+a(1+\delta-\theta) \lambda_{2}\right)}{\gamma(f+\gamma)\left(\lambda_{1}-\lambda_{2}\right)},
$$

the optimal service level of ISV in centralized decision is higher than in decentralized decision.
The optimal service level difference of the dealer in centralized decision and in decentralized decision is 


$$
\Delta s_{2}=\frac{f \gamma(f+2 \gamma)\left(p-\beta_{1}\right) \lambda_{2}+(f+\gamma) \lambda_{1}\left((f+\gamma)\left(-f p-\gamma \beta_{1}+(f+\gamma) \beta_{2}\right)+a(-1-\delta+\theta) \lambda_{2}\right)}{\lambda_{2}\left(-2(f+\gamma)^{2} \lambda_{1}+\gamma^{2} \lambda_{2}\right)} .
$$

If

$$
\beta_{1}>\frac{\left(f p \gamma(f+2 \gamma) \lambda_{2}-(f+\gamma) \lambda_{1}\left(f p(f+\gamma)-(f+\gamma)^{2} \beta_{2}+a(1+\delta-\theta) \lambda_{2}\right)\right)}{\left(\gamma(f+\gamma)^{2} \lambda_{1}+f \gamma(f+2 \gamma) \lambda_{2}\right)},
$$

the optimal service level of the dealer in centralized decision is higher than in decentralized decision.

\section{Extensive Research}

\subsection{ISV Integrated Service Pattern}

Hypothesis 1: The dealer decides to its service level, the ISV is in charge of the customer service of direct channel and the dealer's channel. Because of internet transparency and visibility, and the dealer in close contact with customers, the dealer can easily observe ISV service level. We suppose the dealer have complete information of ISV service.

Hypothesis 2: The ISV is responsible for mixed channel customer service, and by adjusting the wholesale price to compensate its expenditure for customer service.

The profit function of ISV and the dealer is respectively as follows:

$$
\begin{aligned}
& \pi_{1}=\left(p-\beta_{1}\right) D_{1}+\left(w-\beta_{1}\right) D_{2}-\lambda_{1} s_{1}^{2} / 2 \\
& \pi_{2}=(p-w) D_{2}-\lambda_{2} s_{2}^{2} / 2
\end{aligned}
$$

In centralized decision, the optimal service level of ISV is

$s_{1}^{*}=\frac{f\left(p-\beta_{1}\right)}{\lambda_{1}}$, the optimal service level of dealer is $s_{2}^{*}=\frac{f\left(p-\beta_{1}\right)}{\lambda_{2}}$, and the optimal profit of supply chain is $\pi^{*}=\frac{\left(p-\beta_{1}\right)\left(f^{2}\left(p-\beta_{1}\right) \lambda_{2}+\lambda_{1}\left(f^{2}\left(p-\beta_{1}\right)+2 a(1+\delta) \lambda_{2}\right)\right)}{2 \lambda_{1} \lambda_{2}}$.

Proposition 3: the dealer's optimal response function is $s_{2}(w)=\frac{(f+\gamma)(p-w)}{\lambda_{2}}$, which only rely on ISV's wholesale price, foreign to ISV's service level.

From Proposition 3 we can see that the dealer's service level is the response function of the wholesale price. Because the customer service of the dealer is fulfilled by ISV, the dealer's service level does not need to consider customer service cost, but still relative to its own service level cost.

Proposition 4: when $f>\left(\sqrt{\frac{\lambda_{2}}{2 \lambda_{1}}}-1\right) \gamma$, ISV's optimal decision is

$$
\begin{gathered}
w^{*}=\frac{(f+\gamma)\left(p(f+2 \gamma)+f \beta_{1}\right) \lambda_{1}+\left(-p \gamma(f+\gamma)+f \gamma \beta_{1}+a(1-\theta+\delta) \lambda_{1}\right) \lambda_{2}}{2(f+\gamma)^{2} \lambda_{1}-\gamma^{2} \lambda_{2}}, \\
s_{1}^{*}=\frac{f(f+\gamma)(2 f+3 \gamma)\left(p-\beta_{1}\right)+a \gamma(-1+\theta-\delta) \lambda_{2}}{2(f+\gamma)^{2} \lambda_{1}-\gamma^{2} \lambda_{2}},
\end{gathered}
$$

so the dealer's optimal decision is

$$
s_{2}^{*}=\frac{(f+\gamma)\left(f \gamma\left(\beta_{1}-p\right) \lambda_{2}+\lambda_{1}\left(-f(f+\gamma)\left(p-\beta_{1}\right)+a(1-\theta+\delta) \lambda_{2}\right)\right)}{\lambda_{2}\left(-2(f+\gamma)^{2} \lambda_{1}+\gamma^{2} \lambda_{2}\right)} .
$$

\subsection{The Dealer Integrated Service Pattern}

Hypothesis 1: The ISV decides to its service level, the dealer is in charge of the customer service of direct channel and the dealer's channel. Because of internet transparency and visibility, and the application software is installed in ISV server, the ISV can easily observe the dealer service level. We suppose the ISV have complete information of the dealer service.

Hypothesis 2: The dealer is responsible for mixed channel customer service, and the ISV will adjust the wholesale price to compensate the dealer expenditure for customer service.

The profit function of ISV and the dealer is respectively as follows:

$$
\begin{aligned}
\pi_{1} & =p D_{1}+w D_{2}-\lambda_{1} s_{1}^{2} / 2 \\
\pi_{2} & =(p-w) D_{2}-\left(\beta_{2} D_{2}+\beta_{2} D_{1}+\lambda_{2} s_{2}^{2} / 2\right) \\
& =\left(p-w-\beta_{2}\right) D_{2}-\beta_{2} D_{1}-\lambda_{2} s_{2}^{2} / 2
\end{aligned}
$$


In centralized decision, the optimal service level of ISV is $s_{1}^{*}=\frac{f p-f \beta_{2}}{\lambda_{1}}$, the optimal service level of dealer is $s_{2}^{*}=\frac{f p-f \beta_{2}}{\lambda_{2}}$, and the optimal profit of supply chain is $\pi^{*}=\frac{\left(p-\beta_{2}\right)\left(f^{2}\left(p-\beta_{2}\right) \lambda_{2}+\lambda_{1}\left(f^{2}\left(p-\beta_{2}\right)+2 a(1+\delta) \lambda_{2}\right)\right)}{2 \lambda_{1} \lambda_{2}}$

Proposition 5: the dealer's optimal response function is $s_{2}(w)=\frac{(f+\gamma)(p-w)-f \beta_{2}}{\lambda_{2}}$, which only rely on ISV's wholesale price, foreign to ISV's service level.
From Proposition 5 we can see that in the dealer integrated service pattern, the dealer's service level function is similar to the independent service pattern. The dealer's service level is the response function of the wholesale price, which is different with price competition. In the price competition, the dealer's service level is relative to the price of ISV and the wholesales price. But in service competition, the dealer's service level is only relative to the wholesales price.

Proposition 6: when $f>\left(\sqrt{\frac{\lambda_{2}}{2 \lambda_{1}}}-1\right) \gamma$, ISV's optimal decision is

$$
\begin{gathered}
w^{*}=\frac{-\gamma p(f+\gamma) \lambda_{2}+\lambda_{1}\left((f+\gamma)\left(p(f+2 \gamma)-f \beta_{2}\right)+a(1-\theta+\delta) \lambda_{2}\right)}{2(f+\gamma)^{2} \lambda_{1}-\gamma^{2} \lambda_{2}}, \\
s_{1}^{*}=\frac{f(f+\gamma)\left(2 f p+3 p \gamma+\gamma \beta_{2}\right)+a \gamma(-1+\theta-\delta) \lambda_{2}}{2(f+\gamma)^{2} \lambda_{1}-\gamma^{2} \lambda_{2}},
\end{gathered}
$$

so the dealer's optimal decision is

$$
s_{2}^{*}=-\frac{f \gamma\left(p(f+\gamma)+\gamma \beta_{2}\right) \lambda_{2}+(f+\gamma) \lambda_{1}\left(f(f+\gamma)\left(p-\beta_{2}\right)-a(1-\theta+\delta) \lambda_{2}\right)}{\lambda_{2}\left(-2(f+\gamma)^{2} \lambda_{1}+\gamma^{2} \lambda_{2}\right)} .
$$

\subsection{Comparison of the Three Service Pattern}

\subsubsection{Comparison of Independent Service Pattern and ISV Integrated Service Pattern}

1) Comparison of centralized decision.

Compared the supply chain optimal profit in ISV integrated service pattern with independent service pattern in centralized decision, we get:

$$
\Delta \pi=\frac{\left(\beta_{1}-\beta_{2}\right)\left(\gamma\left(2 f p-(2 f+\gamma) \beta_{1}+\gamma \beta_{2}\right) \lambda_{2}+\lambda_{1}\left((f+\gamma)\left(-2 f p+(f-\gamma) \beta_{1}+(f+\gamma) \beta_{2}\right)-2 a(1+\delta-\theta) \lambda_{2}\right)\right)}{2 \lambda_{1} \lambda_{2}}
$$

Through analysis the supply chain optimal profit difference between ISV integrated service pattern and independent service pattern in centralized decision, we get deductions 1.
Deductions 1: In centralized decision, from the perspective of SaaS supply chain, when the parameters accord with one of the following conditions, ISV integrated service pattern is better than the independent service pattern.

1) $f>\gamma, \lambda_{1}>\frac{(2 f+\gamma) \gamma \lambda_{2}}{(f-\gamma)(f+\gamma)}$,

$$
\beta_{1}>\frac{-\gamma\left(2 f p+\gamma \beta_{2}\right) \lambda_{2}+\lambda_{1}\left(2 f p(f+\gamma)-(f+\gamma)^{2} \beta_{2}+2 a(1+\delta-\theta) \lambda_{2}\right)}{(f-\gamma)(f+\gamma) \lambda_{1}-\gamma(2 f+\gamma) \lambda_{2}} .
$$

2) $f>\gamma, \lambda_{1}>\frac{(2 f+\gamma) \gamma \lambda_{2}}{(f-\gamma)(f+\gamma)}, \beta_{1}<\beta_{2}$.

3) $f>\gamma, \lambda_{1}<\frac{f \gamma\left(p-\beta_{2}\right) \lambda_{2}}{f(f+\gamma)\left(p-\beta_{2}\right)+a(1+\delta-\theta) \lambda_{2}}$,

$$
\beta_{2}<\beta_{1}<\frac{-\gamma\left(2 f p+\gamma \beta_{2}\right) \lambda_{2}+\lambda_{1}\left(2 f p(f+\gamma)-(f+\gamma)^{2} \beta_{2}+2 a(1+\delta-\theta) \lambda_{2}\right)}{(f-\gamma)(f+\gamma) \lambda_{1}-\gamma(2 f+\gamma) \lambda_{2}} .
$$


4) $f>\gamma, \frac{(2 f+\gamma) \gamma \lambda_{2}}{(f-\gamma)(f+\gamma)}>\lambda_{1}>\frac{f \gamma\left(p-\beta_{2}\right) \lambda_{2}}{f(f+\gamma)\left(p-\beta_{2}\right)+a(1+\delta-\theta) \lambda_{2}}$,

or

$$
\begin{aligned}
& f<\gamma, \lambda_{1}>\frac{f \gamma\left(p-\beta_{2}\right) \lambda_{2}}{f(f+\gamma)\left(p-\beta_{2}\right)+a(1+\delta-\theta) \lambda_{2}}, \\
& \beta_{2}>\beta_{1}>\frac{-\gamma\left(2 f p+\gamma \beta_{2}\right) \lambda_{2}+\lambda_{1}\left(2 f p(f+\gamma)-(f+\gamma)^{2} \beta_{2}+2 a(1+\delta-\theta) \lambda_{2}\right)}{(f-\gamma)(f+\gamma) \lambda_{1}-\gamma(2 f+\gamma) \lambda_{2}} .
\end{aligned}
$$

The conclusions counter intuitive. Intuitively, if service cost of ISV is lower than its dealer, the ISV integrated service pattern should be better than independent service pattern. But the deduction conclusion is not so simple, for example, sufficient conditions 2), 4), ISV service cost is lower than its dealers, but if the other two conditions are not satisfied, the ISV integrated service will not be better than independent service pattern. And when ISV service cost higher than its dealers', in some cases, the ISV integrated service pattern is also better than in-

dependent service pattern.

2) Comparison of decentralized decision.

Through analysis the supply chain optimal profit difference between ISV integrated service pattern and independent service pattern in decentralized decision, we get deductions 2 .

Deductions 2: In decentralized decision, from the perspective of SaaS supply chain, when the parameters accord with one of the following conditions, the independent service pattern is better than ISV integrated service pattern.

1) $\left((f+\gamma)^{2} \lambda_{1}\left(\left(6 f^{2}+13 f \gamma-\gamma^{2}\right)+\sqrt{36 f^{4}+84 f^{3} \gamma+97 f^{2} \gamma^{2}+94 f \gamma^{3}+13 \gamma^{4}}\right)\right) \times\left(2 \gamma^{2}\left(6 f^{2}+11 f \gamma+\gamma^{2}\right)\right)^{-1}>\lambda_{2}$

$$
\begin{aligned}
>\left((f)^{2}\right. & \left.\lambda_{1}\left(\left(6 f^{2}+13 f \gamma-\gamma^{2}\right)-\sqrt{36 f^{4}+84 f^{3} \gamma+97 f^{2} \gamma^{2}+94 f \gamma^{3}+13 \gamma^{4}}\right)\right) \times\left(2 \gamma^{2}\left(6 f^{2}+11 f \gamma+\gamma^{2}\right)\right)^{-1} \\
\beta_{1}> & \left(\gamma^{3}\left(2 f p(3 f+5 \gamma)+\gamma(f+\gamma) \beta_{2}\right) \lambda_{2}^{2}+3(f+\gamma)^{3} \lambda_{1}^{2}\left(2 f p(f+\gamma)-(f+\gamma)^{2} \beta_{2}+2 a(1+\delta-\theta) \lambda_{2}\right)\right. \\
& \left.\left.+\gamma(f+\gamma) \lambda_{1} \lambda_{2}\left(-2 f p(f+\gamma)(3 f+7 \gamma)+\gamma(f+\gamma)^{2} \beta_{2}-6 a \gamma(1+\delta-\theta) \lambda_{2}\right)\right)\right) \\
& \times\left(3(f-\gamma)(f+\gamma)^{4} \lambda_{1}^{2}+\gamma(f+\gamma)^{2}\left(-6 f^{2}-13 f \gamma+\gamma^{2}\right) \lambda_{1} \lambda_{2}+\gamma^{3}\left(6 f^{2}+11 f \gamma+\gamma^{2}\right) \lambda_{2}^{2}\right)^{-1}
\end{aligned}
$$

$\beta_{1}>\beta_{2}$.

2) $\lambda_{2}>\frac{(\sqrt{13}-1)(f+\gamma)^{2} \lambda_{1}}{2 \gamma^{2}}$,

$$
\begin{gathered}
\begin{array}{c}
\beta_{1}< \\
\left(\gamma^{3}\left(2 f p(3 f+5 \gamma)+\gamma(f+\gamma) \beta_{2}\right) \lambda_{2}^{2}+3(f+\gamma)^{3} \lambda_{1}^{2}\left(2 f p(f+\gamma)-(f+\gamma)^{2} \beta_{2}+2 a(1+\delta-\theta) \lambda_{2}\right)\right. \\
\left.+\gamma(f+\gamma) \lambda_{1} \lambda_{2}\left(-2 f p(f+\gamma)(3 f+7 \gamma)+\gamma(f+\gamma)^{2} \beta_{2}-6 a \gamma(1+\delta-\theta) \lambda_{2}\right)\right) \\
\quad \times\left(3(f-\gamma)(f+\gamma)^{4} \lambda_{1}^{2}+\gamma(f+\gamma)^{2}\left(-6 f^{2}-13 f \gamma+\gamma^{2}\right) \lambda_{1} \lambda_{2}+\gamma^{3}\left(6 f^{2}+11 f \gamma+\gamma^{2}\right) \lambda_{2}^{2}\right)^{-1}
\end{array} \\
\quad f>0.1 \gamma, \lambda_{2}<\frac{\gamma^{2} \lambda_{1}\left(\left(6 f^{2}+15 f \gamma+\gamma^{2}\right)+\sqrt{36 f^{4}+108 f^{3} \gamma+201 f^{2} \gamma^{2}+150 f \gamma^{3}-11 \gamma^{4}}\right)}{2 \gamma^{2}\left(6 f^{2}+9 f \gamma-\gamma^{2}\right)}, \\
\beta_{2}>\frac{2\left(f p \gamma^{3}(3 f+5 \gamma) \lambda_{2}^{2}+3(f+\gamma)^{3} \lambda_{1}^{2}\left(f p(f+\gamma)+a(1+\delta-\theta) \lambda_{2}\right)-\gamma(f+\gamma) \lambda_{1} \lambda_{2}\left(f p(f+\gamma)(3 f+7 \gamma)+3 a \gamma(1+\delta-\theta) \lambda_{2}\right)\right)}{3(f+\gamma)^{5} \lambda_{1}^{2}-\gamma^{2}(f+\gamma)^{3} \lambda_{1} \lambda_{2}-\gamma^{4}(f+\gamma) \lambda_{2}^{2}} ; \\
\beta_{2}<\frac{2 f p \gamma^{3}(3 f+5 \gamma) \lambda_{2}^{2}+6(f+\gamma)^{3} \lambda_{1}^{2}\left(f p(f+\gamma)+a(1+\delta-\theta) \lambda_{2}\right)+2 \gamma(f+\gamma) \lambda_{1} \lambda_{2}\left(-f p(f+\gamma)(3 f+7 \gamma)-3 a \gamma(1+\delta-\theta) \lambda_{2}\right)}{\left.2 f(f+\gamma)^{4} \lambda_{1}^{2}-\gamma(f+\gamma)^{2}(3 f+7 \gamma) \lambda_{1} \lambda_{2}+\gamma^{3}(3 f+5 \gamma) \lambda_{2}^{2}\right)} .
\end{gathered}
$$


3) $\frac{(\sqrt{13}-1)(f+\gamma)^{2} \lambda_{1}}{2 \gamma^{2}}>\lambda_{2}$,

$$
\lambda_{2}>\frac{\gamma(f+\gamma)^{2} \lambda_{1}\left(\left(6 f^{2}+15 f \gamma+\gamma^{2}\right)+\sqrt{36 f^{4}+108 f^{3} \gamma+201 f^{2} \gamma^{2}+150 f \gamma^{3}-11 \gamma^{4}}\right)}{2 \gamma^{2}\left(6 f^{2}+9 f \gamma-\gamma^{2}\right)}
$$

or $\lambda_{2}<\frac{\gamma(f+\gamma)^{2} \lambda_{1}\left(\left(6 f^{2}+15 f \gamma+\gamma^{2}\right)-\sqrt{36 f^{4}+108 f^{3} \gamma+201 f^{2} \gamma^{2}+150 f \gamma^{3}-11 \gamma^{4}}\right)}{2 \gamma^{2}\left(6 f^{2}+9 f \gamma-\gamma^{2}\right)}$,

$$
\begin{aligned}
\beta_{1}< & \left(\gamma^{3}\left(2 f p(3 f+5 \gamma)+\gamma(f+\gamma) \beta_{2}\right) \lambda_{2}^{2}+3(f+\gamma)^{3} \lambda_{1}^{2}\left(2 f p(f+\gamma)-(f+\gamma)^{2} \beta_{2}+2 a(1+\delta-\theta) \lambda_{2}\right)\right. \\
& \left.+\gamma(f+\gamma) \lambda_{1} \lambda_{2}\left(-2 f p(f+\gamma)(3 f+7 \gamma)+\gamma(f+\gamma)^{2} \beta_{2}-6 a \gamma(1+\delta-\theta) \lambda_{2}\right)\right) \\
& \times\left(3(f-\gamma)(f+\gamma)^{4} \lambda_{1}^{2}+\gamma(f+\gamma)^{2}\left(-6 f^{2}-13 f \gamma+\gamma^{2}\right) \lambda_{1} \lambda_{2}+\gamma^{3}\left(6 f^{2}+11 f \gamma+\gamma^{2}\right) \lambda_{2}^{2}\right)^{-1} \\
f> & 0.1 \gamma, . \lambda_{2}>\frac{\gamma(f+\gamma)^{2} \lambda_{1}\left(\left(6 f^{2}+15 f \gamma+\gamma^{2}\right)+\sqrt{36 f^{4}+108 f^{3} \gamma+201 f^{2} \gamma^{2}+150 f \gamma^{3}-11 \gamma^{4}}\right)}{2 \gamma^{2}\left(6 f^{2}+9 f \gamma-\gamma^{2}\right)},
\end{aligned}
$$

$\beta_{2}<\frac{2 f p \gamma^{3}(3 f+5 \gamma) \lambda_{2}^{2}+6(f+\gamma)^{3} \lambda_{1}^{2}\left(f p(f+\gamma)+a(1+\delta-\theta) \lambda_{2}\right)+2 \gamma(f+\gamma) \lambda_{1} \lambda_{2}\left(-f p(f+\gamma)(3 f+7 \gamma)-3 a \gamma(1+\delta-\theta) \lambda_{2}\right)}{2 f\left(3(f+\gamma)^{4} \lambda_{1}^{2}-\gamma(f+\gamma)^{2}(3 f+7 \gamma) \lambda_{1} \lambda_{2}+\gamma^{3}(3 f+5 \gamma) \lambda_{2}^{2}\right)}$.

4) $\frac{(\sqrt{13}-1)(f+\gamma)^{2} \lambda_{1}}{2 \gamma^{2}}>\lambda_{2}$,

$$
\lambda_{2}>\frac{(f+\gamma)^{2} \lambda_{1}\left(\left(6 f^{2}+13 f \gamma-\gamma^{2}\right)+\sqrt{36 f^{4}+84 f^{3} \gamma+97 f^{2} \gamma^{2}+94 f \gamma^{3}+13 \gamma^{4}}\right)}{2 \gamma^{2}\left(6 f^{2}+11 f \gamma+\gamma^{2}\right)}
$$

or $\lambda_{2}<\frac{(f+\gamma)^{2} \lambda_{1}\left(\left(6 f^{2}+13 f \gamma-\gamma^{2}\right)-\sqrt{36 f^{4}+84 f^{3} \gamma+97 f^{2} \gamma^{2}+94 f \gamma^{3}+13 \gamma^{4}}\right)}{2 \gamma^{2}\left(6 f^{2}+11 f \gamma+\gamma^{2}\right)}$,

$$
\begin{aligned}
\beta_{1}< & \left(\gamma^{3}\left(2 f p(3 f+5 \gamma)+\gamma(f+\gamma) \beta_{2}\right) \lambda_{2}^{2}+3(f+\gamma)^{3} \lambda_{1}^{2}\left(2 f p(f+\gamma)-(f+\gamma)^{2} \beta_{2}+2 a(1+\delta-\theta) \lambda_{2}\right)\right. \\
& \left.+\gamma(f+\gamma) \lambda_{1} \lambda_{2}\left(-2 f p(f+\gamma)(3 f+7 \gamma)+\gamma(f+\gamma)^{2} \beta_{2}-6 a \gamma(1+\delta-\theta) \lambda_{2}\right)\right) \\
& \times\left(3(f-\gamma)(f+\gamma)^{4} \lambda_{1}^{2}+\gamma(f+\gamma)^{2}\left(-6 f^{2}-13 f \gamma+\gamma^{2}\right) \lambda_{1} \lambda_{2}+\gamma^{3}\left(6 f^{2}+11 f \gamma+\gamma^{2}\right) \lambda_{2}^{2}\right)^{-1} \\
f> & 0.1 \gamma, \lambda_{2}<\frac{\gamma(f+\gamma)^{2} \lambda_{1}\left(\left(6 f^{2}+15 f \gamma+\gamma^{2}\right)+\sqrt{36 f^{4}+108 f^{3} \gamma+201 f^{2} \gamma^{2}+150 f \gamma^{3}-11 \gamma^{4}}\right)}{2 \gamma^{2}\left(6 f^{2}+9 f \gamma-\gamma^{2}\right)},
\end{aligned}
$$

$\beta_{2}<\frac{2\left(f p \gamma^{3}(3 f+5 \gamma) \lambda_{2}^{2}+3(f+\gamma)^{3} \lambda_{1}^{2}\left(f p(f+\gamma)+a(1+\delta-\theta) \lambda_{2}\right)-\gamma(f+\gamma) \lambda_{1} \lambda_{2}\left(f p(f+\gamma)(3 f+7 \gamma)+3 a \gamma(1+\delta-\theta) \lambda_{2}\right)\right)}{3(f+\gamma)^{5} \lambda_{1}^{2}-\gamma^{2}(f+\gamma)^{3} \lambda_{1} \lambda_{2}-\gamma^{4}(f+\gamma) \lambda_{2}^{2}}$.

From the supply chain optimal profit difference between the ISV integrated service pattern and the independent service pattern under centralized decision and decentralized decision, when ISV service cost is the same as its dealer service cost, no matter centralized decision or decentralized decision, the supply chain optimal profit in the ISV integrated service pattern is the same as the independent service pattern. 


\subsubsection{Comparison of ISV Integrated Service Pattern and Dealer Integrated Service Pattern}

1) Comparison of centralized decision.
Compared the supply chain optimal profit in ISV integrated service pattern with dealer integrated service pattern in centralized decision, we get:

$$
\Delta \pi=\left(\left(\beta_{1}-\beta_{2}\right)\left(f^{2}\left(-2 p+\beta_{1}+\beta_{2}\right) \lambda_{2}+\lambda_{1}\left(f^{2}\left(-2 p+\beta_{1}+\beta_{2}\right)-2 a(1+\delta) \lambda_{2}\right)\right)\right) / 2 \lambda_{1} \lambda_{2}
$$

Through analysis the supply chain optimal profit difference between ISV integrated service pattern and dealer integrated service pattern in centralized decision, we get deductions 3.

Deductions 3: In centralized decision, from the perspective of SaaS supply chain, when the parameters accord with one of the following conditions, ISV integrated service pattern is better than the dealer integrated service pattern.

1) $\beta_{1}>\frac{f^{2}\left(2 p-\beta_{2}\right) \lambda_{2}+\lambda_{1}\left(f^{2}\left(2 p-\beta_{2}\right)+2 a(1+\delta) \lambda_{2}\right)}{f^{2}\left(\lambda_{1}+\lambda_{2}\right)}$;

2) $\beta_{1}<\beta_{2}$.

From the Deductions 3, we can see that when ISV service cost is lower than dealer service cost, The ISV integrated service pattern is better than the dealer integrated service pattern. When ISV service cost is more than a particular value, ISV integrated service is still better than the dealer integrated service pattern, but the particular value is bigger than the dealer service cost. It illustrate that the advantage of service pattern doesn't not only rely on service cost. Because if the ISV service cost is lower than the dealer, the ISV integrated service pattern is better than the dealer integrated service pattern, but if the dealer service cost is lower than the ISV, the dealer integrated service pattern is not always better than the ISV integrated service pattern. The dealer integrated service pattern is better than the ISV integrated service pattern in a particular open interval.

2) Comparison of decentralized decision.

Through analysis the supply chain optimal profit difference between ISV integrated service pattern and dealer integrated service pattern in decentralized decision, we get deductions 4 .

Deductions 4: In decentralized decision, from the perspective of SaaS supply chain, when the parameters accord with one of the following conditions, the ISV integrated service pattern is better than the dealer integrated service pattern.

1) $\lambda_{2}<\frac{(f+\gamma)\left(4 f^{2}+10 f \gamma+3 \gamma^{2}\right) \lambda_{1}-\left(2 f^{2}+5 f \gamma+3 \gamma^{2} 2 f^{2}+5 f \gamma+3 \gamma^{2}\right) \lambda_{1} \sqrt{4 f^{2}+8 f \gamma+13 \gamma^{2}}}{2 \gamma^{2}(5 f+9 \gamma)}$

or $\lambda_{2}>\frac{(f+\gamma)\left(4 f^{2}+10 f \gamma+3 \gamma^{2}\right) \lambda_{1}+\left(2 f^{2}+5 f \gamma+3 \gamma^{2}\right) \lambda_{1} \sqrt{4 f^{2}+8 f \gamma+13 \gamma^{2}}}{2 \gamma^{2}(5 f+9 \gamma)}, \beta^{-}<\beta_{1}<\beta^{+}$;

2) $\frac{(f+\gamma)\left(4 f^{2}+10 f \gamma+3 \gamma^{2}\right) \lambda_{1}-\left(2 f^{2}+5 f \gamma+3 \gamma^{2} 2 f^{2}+5 f \gamma+3 \gamma^{2}\right) \lambda_{1} \sqrt{4 f^{2}+8 f \gamma+13 \gamma^{2}}}{2 \gamma^{2}(5 f+9 \gamma)}<\lambda_{2}$

and $\lambda_{2}<\frac{(f+\gamma)\left(4 f^{2}+10 f \gamma+3 \gamma^{2}\right) \lambda_{1}+\left(2 f^{2}+5 f \gamma+3 \gamma^{2}\right) \lambda_{1} \sqrt{4 f^{2}+8 f \gamma+13 \gamma^{2}}}{2 \gamma^{2}(5 f+9 \gamma)}, \beta^{-}>\beta_{1}$ or $\beta_{1}>\beta^{+}$.

$$
\begin{aligned}
\beta^{-}= & \left(-\left(2 \left(3 f^{2} p(f+\gamma)^{4} \lambda_{1}^{2}+(f+\gamma)^{2} \lambda_{1}\left(f^{2} p\left(4 f^{2}+10 f \gamma+3 \gamma^{2}\right)+a(f+\gamma)(4 \gamma(1+\delta)+f(3+3 \delta+\theta)) \lambda_{1}\right) \lambda_{2}\right.\right.\right. \\
& \left.-\gamma(f+\gamma)\left(f^{2} p \gamma(5 f+9 \gamma)+a\left(\left(-f^{2}+f \gamma+4 \gamma^{2}\right)(1+\delta)+f(f+3 \gamma) \theta\right) \lambda_{1}\right) \lambda_{2}^{2}+a \gamma^{3}((f+\gamma)(1+\delta)-f \theta) \lambda_{2}^{3}\right) \\
& -\sqrt{ }\left(-4 f^{2}(f+\gamma) \beta_{2}\left(-3(f+\gamma)^{3} \lambda_{1}^{2}-(f+\gamma)\left(4 f^{2}+10 f \gamma+3 \gamma^{2}\right) \lambda_{1} \lambda_{2}+\gamma^{2}(5 f+9 \gamma) \lambda_{2}^{2}\right) 3 f^{2}(f+\gamma)^{4}\left(-2 p+\beta_{2}\right) \lambda_{1}^{2}\right. \\
& -(f+\gamma)^{2} \lambda_{1}\left(f^{2}\left(2 p\left(4 f^{2}+11 f \gamma+5 \gamma^{2}\right)+\gamma(4 f+9 \gamma) \beta_{2}\right)+2 a(f+\gamma)(4 \gamma(1+\delta)+f(3+3 \delta+\theta)) \lambda_{1}\right) \lambda_{2} \\
& +\gamma\left(f^{2} \gamma\left(2 p\left(2 f^{2}+4 f \gamma+\gamma^{2}\right)+\gamma(2 f+3 \gamma) \beta_{2}\right)+2 a(f+\gamma)\left(\left(2 f^{2}+7 f \gamma+4 \gamma^{2}\right)(1+\delta)-f(2 f+3 \gamma) \theta\right) \lambda_{1}\right) \lambda_{2}^{2} \\
& \left.-2 a \gamma^{3}((f+\gamma)(1+\delta)-f \theta) \lambda_{2}^{3}\right)+4\left(3 f^{2} p(f+\gamma)^{4} \lambda_{1}^{2}+(f+\gamma)^{2} \lambda_{1}\left(f^{2} p\left(4 f^{2}+10 f \gamma+3 \gamma^{2}\right)\right.\right. \\
& \left.\left.\left.+a(f+\gamma)(4 \gamma(1+\delta)+f(3+3 \delta+\theta))) \lambda_{1}\right) \lambda_{2}-\gamma(f+\gamma)\left(f^{2} p \gamma(5 f+9 \gamma)+a\left(\left(4 f^{2}+10 f \gamma+3 \gamma^{2}-f \theta\right) \lambda_{2}^{3}\right)^{2}\right)\right)\right) \\
& \times\left(2 f^{2}(f+\gamma)\left(-3(f+\gamma)^{3} \lambda_{1}^{2}-(f+\gamma)\left(4 f^{2}+10 f \gamma+3 \gamma^{2}\right) \lambda_{1} \lambda_{2}+\gamma^{2}(5 f+9 \gamma) \lambda_{2}^{2}\right)\right)^{-1}
\end{aligned}
$$




$$
\begin{aligned}
\beta^{+}= & \left(-\left(2 \left(3 f^{2} p(f+\gamma)^{4} \lambda_{1}^{2}+(f+\gamma)^{2} \lambda_{1}\left(f^{2} p\left(4 f^{2}+10 f \gamma+3 \gamma^{2}\right)+a(f+\gamma) 4 \gamma(1+\delta)+f(3+3 \delta+\theta) \lambda_{1}\right) \lambda_{2}\right.\right.\right. \\
& \left.-\gamma(f+\gamma)\left(f^{2} p \gamma(5 f+9 \gamma)+a\left(\left(-f^{2}+f \gamma+4 \gamma^{2}\right)(1+\delta)+f(f+3 \gamma) \theta\right) \lambda_{1}\right) \lambda_{2}^{2}+a \gamma^{3}((f+\gamma)(1+\delta)-f \theta) \lambda_{2}^{3}\right) \\
& +\sqrt{ }\left(-4 f^{2}(f+\gamma) \beta_{2}\left(-3(f+\gamma)^{3} \lambda_{1}^{2}-(f+\gamma)\left(4 f^{2}+10 f \gamma+3 \gamma^{2}\right) \lambda_{1} \lambda_{2}+\gamma^{2}(5 f+9 \gamma) \lambda_{2}^{2}\right)\left(3 f^{2}(f+\gamma)^{4}\left(-2 p+\beta_{2}\right) \lambda_{1}^{2}\right.\right. \\
& -(f+\gamma)^{2} \lambda_{1}\left(f^{2}\left(2 p\left(4 f^{2}+11 f \gamma+5 \gamma^{2}\right)+\gamma(4 f+9 \gamma) \beta_{2}\right)+2 a(f+\gamma)(4 \gamma(1+\delta)+f(3+3 \delta+\theta)) \lambda_{1}\right) \lambda_{2} \\
& +\gamma\left(f^{2} \gamma\left(2 p\left(2 f^{2}+4 f \gamma+\gamma^{2}\right)+\gamma(2 f+3 \gamma) \beta_{2}\right)+2 a(f+\gamma)\left(\left(2 f^{2}+7 f \gamma+4 \gamma^{2}\right)(1+\delta)-f(2 f+3 \gamma) \theta\right) \lambda_{1}\right) \lambda_{2}^{2} \\
& \left.-2 a \gamma^{3}((f+\gamma)(1+\delta)-f \theta) \lambda_{2}^{3}\right)+4\left(3 f^{2} p(f+\gamma)^{4} \lambda_{1}^{2}+(f+\gamma)^{2} \lambda_{1}\left(f^{2} p\left(4 f^{2}+10 f \gamma+3 \gamma^{2}\right)\right.\right. \\
& \left.\left.\left.\left.\left.+a\left(f-f^{2}+f \gamma+4 \gamma^{2}\right)(1+\delta)+f(f+3 \gamma) \theta\right) \lambda_{1}\right) \lambda_{2}^{2}+a \gamma^{3}((f+\gamma)(1+\delta)-f \theta) \lambda_{2}^{3}\right)^{2}\right)\right) \\
& \times\left(2 f^{2}(f+\gamma)\left(-3(f+\gamma)^{3} \lambda_{1}^{2}-(f+\gamma)\left(4 f^{2}+10 f \gamma+3 \gamma^{2}\right) \lambda_{1} \lambda_{2}+\gamma^{2}(5 f+9 \gamma) \lambda_{2}^{2}\right)\right)^{-1}
\end{aligned} .
$$

From the supply chain optimal profit difference between the ISV integrated service pattern and the dealer integrated service pattern under centralized decision, when ISV service cost is the same as its dealer service cost, in centralized decision, the supply chain optimal profit in the ISV integrated service pattern is the same as the dealer integrated service pattern.

In decentralized decision, when ISV service cost is the same as the dealer service cost, if the parameters accord with one of the following conditions, the supply chain optimal profit in ISV integrated service pattern is the same as in the dealer integrated service pattern.
1) $\lambda_{2}<\frac{f(f+\gamma)(2 f \beta+(p+3 \beta) \gamma)}{3 a \gamma(1+\delta-\theta)}$;
2) $\lambda_{2}>\frac{f(f+\gamma)(2 f \beta+(p+3 \beta) \gamma)}{3 a \gamma(1+\delta-\theta)}$;

$$
\text { 3) } \lambda_{1}<\frac{f \gamma^{2}(-6 f p+5 f \beta-8 p \gamma+6 \beta \gamma) \lambda_{2}}{2(f+\gamma)\left(f(f+\gamma)(2 f \beta+(p+3 \beta) \gamma)-3 a \gamma(1+\delta-\theta) \lambda_{2}\right)} \text {. }
$$

The above analysis results show that in decentralized decision, when ISV service cost is the same as the dealer service cost, which service pattern better relies on the service level cost. When the service level cost of the dealer is lower than the ISV, the dealer integrated service pattern will be better than the ISV integrated service pattern. When the service level cost of the dealer is higher than the ISV, if the service level cost of ISV is lower than a particular value, ISV integrated service pattern is still better than the dealer integrated service pattern.

In conclusion, from the supply chain perspective, any service pattern of SaaS mixed channel doesn't have the overwhelming superiority. When ISV service cost is the same as the dealer service cost, in centralized decision, the supply chain optimal profit in the ISV integrated service pattern is the same as in the dealer integrated service pattern.

\subsubsection{Comparison of Dealer Integrated Service Pattern and Independent Service Pattern}

1) Comparison of centralized decision.

Compared the supply chain optimal profit in dealer integrated service pattern with independent service pattern in centralized decision, we get:

$$
\Delta \pi=\frac{\left(\beta_{1}-\beta_{2}\right)\left((f+\gamma)\left(2 f p-(f+\gamma) \beta_{1}+(-f+\gamma) \beta_{2}\right) \lambda_{2}+\lambda_{1}\left(\gamma\left(-2 f p-\gamma \beta_{1}+(2 f+\gamma) \beta_{2}\right)+2 a \theta \lambda_{2}\right)\right)}{2 \lambda_{1} \lambda_{2}}
$$

Through analysis the supply chain optimal profit difference between dealer integrated service pattern and independent service pattern in centralized decision, we get deductions 5 .
Deductions 5: In centralized decision, from the perspective of SaaS supply chain, when the parameters accord with one of the following conditions, the dealer integrated service pattern is better than the independent service pattern.

$$
\text { 1) } \begin{aligned}
\lambda_{2} & >\frac{f \gamma\left(p-\beta_{2}\right) \lambda_{1}}{f(f+\gamma)\left(p-\beta_{2}\right)+a \theta \lambda_{1}}, \\
\beta_{2} & <\beta_{1}<\frac{(f+\gamma)\left(2 f p+(-f+\gamma) \beta_{2}\right) \lambda_{2}+\lambda_{1}\left(-2 f p \gamma+\gamma(2 f+\gamma) \beta_{2}+2 a \theta \lambda_{2}\right)}{\gamma^{2} \lambda_{1}+(f+\gamma)^{2} \lambda_{2}}
\end{aligned}
$$


2) $\lambda_{2}<\frac{f \gamma\left(p-\beta_{2}\right) \lambda_{1}}{f(f+\gamma)\left(p-\beta_{2}\right)+a \theta \lambda_{1}}$,

$$
\frac{(f+\gamma)\left(2 f p+(-f+\gamma) \beta_{2}\right) \lambda_{2}+\lambda_{1}\left(-2 f p \gamma+\gamma(2 f+\gamma) \beta_{2}+2 a \theta \lambda_{2}\right)}{\gamma^{2} \lambda_{1}+(f+\gamma)^{2} \lambda_{2}}<\beta_{1}<\beta_{2} .
$$

From the Deduction 5, we can see that when dealer service cost is lower than ISV service cost and the service level parameter of the dealer is higher than a particular value. The dealer integrated service pattern is better than the independent integrated service pattern. When dealer service cost is higher than ISV service cost and the service level parameter of the dealer is lower than the particular value. The dealer integrated service pattern is also better than the independent integrated service pattern. It illustrate that the advantage of service pattern doesn't only rely on service cost.
2) Comparison of decentralized decision.

Through analysis the supply chain optimal profit difference between dealer integrated service pattern and independent service pattern in decentralized decision, we get deductions 6 .

Deductions 2: In decentralized decision, from the perspective of SaaS supply chain, when the parameters accord with one of the following conditions, the independent service pattern is better than dealer integrated service pattern.

1) if

$$
\lambda_{2}<\frac{\left(4 f^{4}+16 f^{3} \gamma+22 f^{2} \gamma^{2}+12 f \gamma^{3}-\gamma^{4}\right) \lambda_{1}-\left(2 f^{2}+4 f \gamma+\gamma^{2}\right) \lambda_{1} \sqrt{4 f^{4}+16 f^{3} \gamma+22 f^{2} \gamma^{2}+16 f \gamma^{3}+13 \gamma^{4}}}{2 \gamma^{2}\left(5 f^{2}+10 f \gamma+\gamma^{2}\right)}
$$

or

$$
\lambda_{2}>\frac{\left(4 f^{4}+16 f^{3} \gamma+22 f^{2} \gamma^{2}+12 f \gamma^{3}-\gamma^{4}\right) \lambda_{1}+\left(2 f^{2}+4 f \gamma+\gamma^{2}\right) \lambda_{1} \sqrt{4 f^{4}+16 f^{3} \gamma+22 f^{2} \gamma^{2}+16 f \gamma^{3}+13 \gamma^{4}}}{2 \gamma^{2}\left(5 f^{2}+10 f \gamma+\gamma^{2}\right)},
$$

$\beta^{-}>\beta_{1}$ or $\beta_{1}>\beta^{+}$;

2) if

$$
\lambda_{2}>\frac{\left(4 f^{4}+16 f^{3} \gamma+22 f^{2} \gamma^{2}+12 f \gamma^{3}-\gamma^{4}\right) \lambda_{1}-\left(2 f^{2}+4 f \gamma+\gamma^{2}\right) \lambda_{1} \sqrt{4 f^{4}+16 f^{3} \gamma+22 f^{2} \gamma^{2}+16 f \gamma^{3}+13 \gamma^{4}}}{2 \gamma^{2}\left(5 f^{2}+10 f \gamma+\gamma^{2}\right)}
$$

or

$$
\lambda_{2}<\frac{\left(4 f^{4}+16 f^{3} \gamma+22 f^{2} \gamma^{2}+12 f \gamma^{3}-\gamma^{4}\right) \lambda_{1}+\left(2 f^{2}+4 f \gamma+\gamma^{2}\right) \lambda_{1} \sqrt{4 f^{4}+16 f^{3} \gamma+22 f^{2} \gamma^{2}+16 f \gamma^{3}+13 \gamma^{4}}}{2 \gamma^{2}\left(5 f^{2}+10 f \gamma+\gamma^{2}\right)},
$$

$$
\begin{aligned}
\beta^{-}< & \beta_{1}<\beta^{+} ; \\
\beta^{-}= & \left(-\left(2 \left(3 \gamma(f+\gamma)^{4}\left(-f p+(f+\gamma) \beta_{2}\right) \lambda_{1}^{2}+(f+\gamma)^{2} \lambda_{1}\left(f p\left(4 f^{3}+13 f^{2} \gamma+13 f \gamma^{2}+7 \gamma^{3}\right)\right.\right.\right.\right. \\
& \left.+(f+\gamma)\left(\gamma\left(3 f^{2}+6 f \gamma-\gamma^{2}\right) \beta_{2}+a(\gamma+\gamma \delta+4 f \theta+3 \gamma \theta) \lambda_{1}\right)\right) \lambda_{2}-\gamma(f+\gamma)\left(\gamma \left(f p\left(5 f^{2}+12 f \gamma+5 \gamma^{2}\right)\right.\right. \\
& \left.\left.+\gamma\left(3 f^{2}+6 f \gamma+\gamma^{2}\right) \beta_{2}\right)+a(-2 f \gamma(1+\delta-3 \theta))+f^{2}(-1-\delta+\theta)+\gamma^{2}(1+\delta+3 \theta) \lambda_{1}\right) \lambda_{2}^{2} \\
& \left.+a \gamma^{3}((f+\gamma)(1+\delta)-f \theta) \lambda_{2}^{3}\right)-\sqrt{ }\left(4 \left(3 \gamma(f+\gamma)^{4}\left(-f p+(f+\gamma) \beta_{2}\right) \lambda_{1}^{2}\right.\right. \\
& \left.+(f+\gamma)^{2} \lambda_{1}\left(f p\left(4 f^{3}+13 f^{2} \gamma+13 f \gamma^{2}+7 \gamma^{3}\right)\right)+(f+\gamma)\left(\gamma\left(3 f^{2}+6 f \gamma-\gamma^{2}\right) \beta_{2}+a(\gamma+\gamma \delta+4 f \theta+3 \gamma \theta) \lambda_{1}\right)\right) \lambda_{2} \\
& -\gamma(f+\gamma)\left(\gamma\left(f p\left(5 f^{2}+12 f \gamma+5 \gamma^{2}\right)+\gamma\left(3 f^{2}+6 f \gamma+\gamma^{2}\right) \beta_{2}\right)+a\left(-2 f \gamma(1+\delta-3 \theta)+f^{2}(-1-\delta+\theta)\right.\right. \\
& \left.\left.+\gamma^{2}(1+\delta+3 \theta) \lambda_{1}\right) \lambda_{2}^{2}+a \gamma^{3}((f+\gamma)(1+\delta)-f \theta) \lambda_{2}^{3}\right)^{2}-4(f+\gamma)^{2} \beta_{2}\left(-3 \gamma^{2}(f+\gamma)^{2} \lambda_{1}^{2}\right. \\
& \left.+\left(-4 f^{4}-16 f^{3} \gamma-22 f^{2} \gamma^{2}-12 f \gamma^{3}+\gamma^{4}\right) \lambda_{1} \lambda_{2}+\gamma^{2}\left(5 f^{2}+10 f \gamma+\gamma^{2}\right) \lambda_{2}^{2}\right)\left(\gamma ^ { 2 } \lambda _ { 2 } ^ { 2 } \left(2 f p\left(2 f^{3}+7 f^{2} \gamma+9 f \gamma^{2}+5 \gamma^{3}\right)\right.\right. \\
& \left.+\gamma\left(2 f^{3}+4 f^{2} \gamma+2 f \gamma^{2}+\gamma^{3}\right) \beta_{2}-2 a \gamma((f+\gamma)(1+\delta)-f \theta) \lambda_{2}\right)+(f+\gamma)^{3} \lambda_{1}^{2}\left(-3 \gamma(f+\gamma)\left(-2 f p+(2 f+\gamma) \beta_{2}\right)\right. \\
& \left.-2 a(4 f \theta+\gamma(1+\delta+3 \theta)) \lambda_{2}\right)+(f+\gamma) \lambda_{1} \lambda_{2}\left(( f + \gamma ) \left(-2 f p\left(4 f^{3}+14 f^{2} \gamma+15 f \gamma^{2}+7 \gamma^{3}\right)\right.\right. \\
& \left.\left.\left.\left.\left.\left.+\gamma\left(-4 f^{3}-8 f^{2} \gamma+2 f \gamma^{2}+\gamma^{3}\right) \beta_{2}\right)+2 a \gamma\left(4 f \gamma(1+\delta)+2 f^{2}(1+\delta-\theta)+\gamma^{2}(1+\delta+3 \theta)\right) \lambda_{2}\right)\right)\right)\right)\right) \\
& +\left(2(f+\gamma)^{2}\left(-3 \gamma^{2}(f+\gamma)^{2} \lambda_{1}^{2}+\left(-4 f^{4}-16 f^{3} \gamma-22 f^{2} \gamma^{2}-12 f \gamma^{3}+\gamma^{4}\right) \lambda_{1} \lambda_{2}+\gamma^{2}\left(5 f^{2}+10 f \gamma+\gamma^{2}\right) \lambda_{2}^{2}\right)\right)
\end{aligned}
$$




$$
\begin{aligned}
& \beta^{+}=\left(-\left(2 \left(3 \gamma(f+\gamma)^{4}\left(-f p+(f+\gamma) \beta_{2}\right) \lambda_{1}^{2}+(f+\gamma)^{2} \lambda_{1}\left(f p\left(4 f^{3}+13 f^{2} \gamma+13 f \gamma^{2}+7 \gamma^{3}\right)\right.\right.\right.\right. \\
& \left.+(f+\gamma)\left(\gamma\left(3 f^{2}+6 f \gamma-\gamma^{2}\right) \beta_{2}+a(\gamma+\gamma \delta+4 f \theta+3 \gamma \theta) \lambda_{1}\right)\right) \lambda_{2} \\
& -\gamma(f+\gamma)\left(\gamma\left(f p\left(5 f^{2}+12 f \gamma+5 \gamma^{2}\right)+\gamma\left(3 f^{2}+6 f \gamma+\gamma^{2}\right) \beta_{2}\right)+a(-2 f \gamma(1+\delta-3 \theta)\right. \\
& \left.\left.+f^{2}(-1-\delta+\theta)+\gamma^{2}(1+\delta+3 \theta) \lambda_{1}\right) \lambda_{2}^{2}+a \gamma^{3}((f+\gamma)(1+\delta)-f \theta) \lambda_{2}^{3}\right) \\
& +\sqrt{ }\left(4 \left(3 \gamma(f+\gamma)^{4}\left(-f p+(f+\gamma) \beta_{2}\right) \lambda_{1}^{2}+(f+\gamma)^{2} \lambda_{1}\left(f p\left(4 f^{3}+13 f^{2} \gamma+13 f \gamma^{2}+7 \gamma^{3}\right)\right.\right.\right. \\
& \left.+(f+\gamma)\left(\gamma\left(3 f^{2}+6 f \gamma-\gamma^{2}\right) \beta_{2}+a(\gamma+\gamma \delta+4 f \theta+3 \gamma \theta) \lambda_{1}\right)\right) \lambda_{2} \\
& -\gamma(f+\gamma)\left(\gamma\left(f p\left(5 f^{2}+12 f \gamma+5 \gamma^{2}\right)+\gamma\left(3 f^{2}+6 f \gamma+\gamma^{2}\right) \beta_{2}\right)+a\left(-2 f \gamma(1+\delta-3 \theta)+f^{2}(-1-\delta+\theta)\right.\right. \\
& \left.\left.+\gamma^{2}(1+\delta+3 \theta) \lambda_{1}\right) \lambda_{2}^{2}+a \gamma^{3}((f+\gamma)(1+\delta)-f \theta) \lambda_{2}^{3}\right)^{2}-4(f+\gamma)^{2} \beta_{2}\left(-3 \gamma^{2}(f+\gamma)^{2} \lambda_{1}^{2}\right. \\
& \left.+\left(-4 f^{4}-16 f^{3} \gamma-22 f^{2} \gamma^{2}-12 f \gamma^{3}+\gamma^{4}\right) \lambda_{1} \lambda_{2}+\gamma^{2}\left(5 f^{2}+10 f \gamma+\gamma^{2}\right) \lambda_{2}^{2}\right)\left(\gamma ^ { 2 } \lambda _ { 2 } ^ { 2 } \left(2 f p\left(2 f^{3}+7 f^{2} \gamma+9 f \gamma^{2}+5 \gamma^{3}\right)\right.\right. \\
& \left.+\gamma\left(2 f^{3}+4 f^{2} \gamma+2 f \gamma^{2}+\gamma^{3}\right) \beta_{2}-2 a \gamma((f+\gamma)(1+\delta)-f \theta) \lambda_{2}\right)+(f+\gamma)^{3} \lambda_{1}^{2}\left(-3 \gamma(f+\gamma)\left(-2 f p+(2 f+\gamma) \beta_{2}\right)\right. \\
& \left.-2 a(4 f \theta+\gamma(1+\delta+3 \theta)) \lambda_{2}\right)+(f+\gamma) \lambda_{1} \lambda_{2}\left(( f + \gamma ) \left(-2 f p\left(4 f^{3}+14 f^{2} \gamma+15 f \gamma^{2}+7 \gamma^{3}\right)\right.\right. \\
& \left.\left.\left.\left.\left.+\gamma\left(-4 f^{3}-8 f^{2} \gamma+2 f \gamma^{2}+\gamma^{3}\right) \beta_{2}\right)+2 a \gamma\left(4 f \gamma(1+\delta)+2 f^{2}(1+\delta-\theta)+\gamma^{2}(1+\delta+3 \theta)\right) \lambda_{2}\right)\right)\right)\right) \\
& \times\left(2(f+\gamma)^{2}\left(-3 \gamma^{2}(f+\gamma)^{2} \lambda_{1}^{2}+\left(-4 f^{4}-16 f^{3} \gamma-22 f^{2} \gamma^{2}-12 f \gamma^{3}+\gamma^{4}\right) \lambda_{1} \lambda_{2}+\gamma^{2}\left(5 f^{2}+10 f \gamma+\gamma^{2}\right) \lambda_{2}^{2}\right)\right)^{-1}
\end{aligned}
$$

From the supply chain optimal profit difference between the dealer integrated service pattern and the independent service pattern under centralized decision, when ISV service cost is the same as its dealer service cost, in centralized decision, the supply chain optimal profit in the dealer integrated service pattern is the same as in the independent service pattern.

In decentralized decision, when ISV service cost is the same as the dealer service cost, if

$$
\lambda_{2}>\frac{f(f+\gamma)(2 f \beta+(p+3 \beta) \gamma)}{3 a \gamma(1+\delta-\theta)}
$$

and

$$
\lambda_{1}>\frac{f \gamma^{2}(-6 f p+5 f \beta-8 p \gamma+6 \beta \gamma) \lambda_{2}}{2(f+\gamma)\left(f(f+\gamma)(2 f \beta+(p+3 \beta) \gamma)-3 a \gamma(1+\delta-\theta) \lambda_{2}\right)},
$$

the dealer integrated service pattern is better than the independent service pattern.

The above analysis results show that in decentralized decision, when ISV service cost is the same as the dealer service cost, which service pattern better relies on the service level parameter. Whether adopt dealer integrated service pattern or independent service pattern, it relies on the service level parameter. When the dealer service level parameter is higher, if the ISV service level parameter is higher than a particular value, the dealer integrated service will be better than the independent service pattern.

\section{Implication and Conclusion}

The difference between Service competition and price competition is quite obvious, such as the dealer service level only rely on wholesale price, no longer subject to ISV service price and service impact. For ISV, whether to establish mixed channel rely on the market segmentation degree and the mixed channel competition degree, say, if the customer channel preference is strong, ISV should not establish mixed-channel.

In independent service pattern, under centralized decision, the service level of ISV and its dealer is impacted directly by the service cost. The high service level is provided by the supply chain member whose service cost is lower. It illustrates that the efficiency of resource allocation is higher under centralized decision. Under decentralized decisions, the service level will be influenced by numerous factors. Although whether the supply chain optimal profit in centralized decisions is more than in decentralized decision can not be judged by the analytic expression intuitively, from the impact of service cost on service level in centralized decision, we can deduct that the resource utilization under centralized decision is more reasonable than decentralized decision. While set up the mixed 
channel, the ISV as the mixed channel leader should apply some tactics to improve the resource utilization under decentralized decision.

From the supply chain profit maximization perspective to compare the three service pattern, any service pattern of SaaS mixed channel doesn't have the overwhelming superiority. When ISV service cost is the same as the dealer service cost, in centralized decision, the supply chain optimal profit in the ISV integrated service pattern is the same as in the dealer integrated service pattern and is same as in the independent service pattern; in decentralized decision, the supply chain optimal profit in ISV integrated service pattern is the same as in the independent service pattern, only when the service level parameter of the dealer and the ISV both high, the dealer integrated service is better than the ISV integrated service pattern and the independent service pattern.

Based on the characteristics SaaS and different service providers in distribution channel, we sort out three different service patterns, independent service, retailer integrated service and the ISV integrated service. We construct service competition model of three service pattern and study the optimizing decision of the ISV and the dealer. Further more, we explore the impact of customer's service sensibility, channel preference, service cost of the ISV and the dealer, and customer base on service competition, and then compared the three service pattern fomr the supply chain profit maximization perspective. We found that 1) the difference between Service competition and price competition is quite obvious, the dealer service level only rely on wholesale price, no longer subject to ISV service price and service impact; 2) for ISV, whether to establish mixed channel rely on the market segmentation degree and the mixed channel competition degree; 3) the resource utilization under centralized decision is more reasonable than decentralized decision; 4) from the supply chain profit maximization perspective, any service pattern of SaaS mixed channel doesn't have the overwhelming superiority. The paper extent the mixed channel research to software service industry and enrich the theory model of dual channel, the result will guide the supply chain member to adjust their decision according to different variables in order to maximization their profits. This paper puts forward three kinds of service pattern, but supply chain optimal profit improvement is limited in adopting the three service pattern, so we should research the contract coordination of SaaS mixed channel under service competition in next step in order to improve the mixed channel supply chain profit.

\section{Acknowledgements}

Thanks to Liu Gan for his constructive suggestions, who is a doctoral candidate in Industry Engineering Department of Pennsylvania state University.

\section{REFERENCES}

[1] P. Tyrväinen and J. Selin, "How to Sell SaaS: A Model for Main Factors of Marketing and Selling Software-as-aService,” Software Business, Vol. 80, No. 2, 2011, pp. 216. doi:10.1007/978-3-642-21544-5_2

[2] C. Pettey, "Gartner Says 25 Percent of New Business Software Will Be Delivered as Software as a Service by 2011," Gartner, Stamford, 2006.

[3] S. A. Mertz, C. Eschinger, T. Eid, H. H. Huang, C. Pang and B. Pring, "Market Trends: Software as a Service, Worldwide,” Gartner, Stamford, 2009.

[4] W.-W. Wu, "Mining Significant Factors Affecting the Adoption of SaaS Using the Rough Set Approach,” Journal of Systems and Software, Vol. 84, No. 3, 2011, pp. 435-441. doi:10.1016/j.jss.2010.11.890

[5] A. A. Benlian, "Transaction Cost Theoretical Analysis of Software-as-a-Service (SAAS)-Based Sourcing in SMBS and Enterprise," Proceedings of 17th European Conference on Information Systems, Verona, 8-12 June 2009, pp. $1-12$.

[6] A. Benlian, T. Hess and P. Buxmann, "Drivers of SaaSAdoption-An Empirical Study of Different Application Types,” Business \& Information Systems Engineering, Vol. 1, No. 5, 2009, pp. 357-369. doi:10.1007/s12599-009-0068-X

[7] R. Mietzner and F. Leymann, "Towards Provisioning the Cloud: On the Usage of Multi-Granularity Flows and Services to Realize a Unified Provisioning Infrastructure for Saas Applications," IEEE Congress on Services Proceedings, Hawaii, 6-11 July 2008, pp. 3-10. doi:10.1109/SERVICES-1.2008.36

[8] M. Fan, S. Kumar and A. B. Whinston, "Short-Term and Long-Term Competition between Providers of ShrinkWrap Software and Software as a Service,” European Journal of Operational Research, Vol. 196, No. 2, 2009, pp. 661-671. doi:10.1016/j.ejor.2008.04.023

[9] H. K. Cheng, Q. C. Tang and J. L. Zhao, "Web Services and Service-Oriented Application Provisioning: An Analytical Study of Application Service Strategies," IEEE Transactions on Engineering Management, Vol. 53, No. 4, 2006, pp. 520-533. doi:10.1109/TEM.2006.883711

[10] S. Bhattacharjee, R. D. Gopal, et al., "Consumer Search and Retailer Strategies in the Presence of Online Music Sharing," Journal of Management Information Systems, Vol. 23, No. 1, 2006, pp. 129-159. doi:10.2753/MIS0742-1222230104

[11] G. W. Hua, T. C. E. Cheng, et al., "Electronic Books: To ' $E$ ' or not to 'E'? A Strategic Analysis of Distribution Channel Choices of Publishers," International Journal of Production Economics, Vol. 129, No. 2, 2010, pp. 338346. doi:10.1016/j.ijpe.2010.11.011

[12] M. Khouja and Y. L. Wang, "The Impact of Digital Channel Distribution on the Experience Goods Industry,” European Journal of Operational Research, Vol. 207, No. 1, 2010, pp. 481-491. doi:10.1016/j.ejor.2010.04.007

[13] Q. Y. Hu, Y. H. Wei, et al., "Revenue Management for a Supply Chain with Two Streams of Customers," European Journal of Operational Research, Vol. 200, No. 2, 
2010, pp. 582-598. doi:10.1016/j.ejor.2009.01.006

[14] W. K. Chiang, D. Chhajed and J. D. Hess, "Direct Marketing, Indirect Profits: A Strategic Analysis of DualChannel Supply-Chain Design,” Management Science, Vol. 49, No. 1, 2003, pp. 1-20. doi:10.1287/mnsc.49.1.1.12749

[15] N. Kumar and R. Ruan, “On Manufacturers Complementing the Traditional Retail Channel with a Direct Online Channel,” Quantitative Marketing and Economics, Vol. 4, No. 3, 2004, pp. 289-323. doi:10.1007/s11129-005-9003-8

[16] M. Khouja, S. Park, et al., "Channel Selection and Pricing in the Presence of Retail-Captive Consumers," International Journal of Production Economics, Vol. 125, No. 1, 2010, pp. 84-95. doi:10.1016/j.jjpe.2010.01.005

[17] S.-J. Li and Z.-G. Zhang, "Performance of Forcast Information Sharing in Dual-Channel Supply Chain," Industrial Engineering \& Management Science, Vol. 15, No. 5, 2010, pp. 40-43.

[18] X. H. Yue and J. Liu, "Demand Forecast Sharing in a Dual-Channel Supply Chain,” European Journal of Operational Research, Vol. 174, No. 1, 2006, pp. 646-667. doi:10.1016/j.ejor.2004.12.020

[19] R.-Z. Qiu, X.-Y. Huang and R.-G. Ge, “The Coordination Model for Online and Traditional Channel in Supply Chain under Information Sharing," Journal of Industry Engineering and Engineering Management, Vol. 23, No. 4, 2009, pp. 74-78.

[20] Y.-J. Guo, D.-G. Qu and L.-Q. Zhao, “Analysis of Pricing Policies of Hybrid Distribution Channels in E-Market," Journal of Systems Engineering, Vol. 23, No. 5, 2008, pp. 570-576.

[21] S. Viswanathan, "Competing across Technology-Differentiated Channels: The Impact of Network Externalities and Switching Costs,” Management Science, Vol. 51, No. 3, 2005, pp. 483-496. doi:10.1287/mnsc.1040.0338

[22] G. Iyer, "Coordinating Channels under Price and NonPrice Competition,” Marketing Science, Vol. 17, No. 4, 1998, pp. 338-355.

[23] A. A. Tsay and N. Agrawal, "Channel Dynamics under Price and Service Competition," Manufacturing \& Service Operations Management, Vol. 2, No. 4, 2000, pp. 372-391. doi:10.1287/msom.2.4.372.12342

[24] Y. Xia and S. M. Gilbert, "Strategic Interactions between Channel Structure and Demand Enhancing Services,” European Journal of Operational Research, Vol. 181, No. 1, 2007, pp. 252-265. doi:10.1016/j.ejor.2006.06.027

[25] S. Devaraj, M. Fan and R. Kohli, “Antecedents of B2C Channel Satisfaction and Preference: Validating E-Commerce Metrics,” Information Systems Research, Vol. 13, No. 3, 2002, pp. 316-333. doi:10.1287/isre.13.3.316.77

[26] A. J. Rohm and V. Swaminathan, “A Typology of Online Shoppers Based on Shopping Motivations," Journal of Business Research, Vol. 57, No. 7, 2004, pp. 748-757. doi:10.1016/S0148-2963(02)00351-X

[27] T. Liang and J. Huang, “An Empirical Study on Consumer Acceptance of Products in Electronic Markets: A Transaction Cost Model,” Decision Support Systems, Vol.
24, No. 1, 1998, pp. 29-43. doi:10.1016/S0167-9236(98)00061-X

[28] F. Reichheld and P. Schefter, "E-Loyalty: Your Secret Weapon on the Web," Harvard Business Review, Vol. 78, No. 4, 2000, pp. 105-113.

[29] J. Shan, R. Dhawan, et al., "Supply Chain Issue in Knowledge-Based Service Industries: Discussion,” Indian Institute of Management Review, Vol. 19, No. 2, 2007, pp. 173-188.

[30] R. Ernst and S. G. Powell, "Manufacturer Incentives to Improve Retail Service Levels,” European Journal of Operational Research, Vol. 104, No. 3, 1998, pp. 437-450. doi:10.1016/S0377-2217(97)00012-X

[31] P. Kotler, "Marketing Management-Analysis, Planning, Implementation, and Control," 9th Edition, Shanghai People’s Publishing House, Shanghai, 1999.

[32] P.-Q. Li, “Channel Competition in 'One-to-Two' Supply Chain Based on Electronic Commerce,” Journal of Industry Engineering and Engineering Management, Vol. 15, No. 03, 2010, pp. 13-18.

[33] C. X. Liu, H. P. Tian, et al., "Incentive Contract Design in Competing Distribution Channels," Production Planning \& Control, Vol. 20, No. 4, 2009, pp. 295-305. doi:10.1080/09537280902843623

[34] F. J. Coelho and C. Easingwood, "Multiple Channel Systems in Services: Pros, Cons and Issues,” The Service Industries Journal, Vol. 24, No. 5, 2004, pp. 1-29. doi:10.1080/0264206042000276810

[35] M. Khouja, S. Park, et al., "Channel Selection and Pricing in the Presence of Retail-Captive Consumers," International Journal of Production Economics, Vol. 125, No. 1, 2010, pp. 84-95. doi:10.1016/j.ijpe.2010.01.005

[36] N. Kumar and R. Ruan, "On Complementing the Retail Channel with a Direct Online Channel," Quantitative Marketing and Economics, Vol. 4, No. 3, 2006, pp. 289-323. doi:10.1007/s11129-005-9003-8

[37] M. Ahuja, B. Gupta and P. Raman, “An Empirical Investigation of Online Consumer Purchasing Behavior," Communications of the ACM, Vol. 46, No. 12, 2003, pp. 145151. doi:10.1145/953460.953494

[38] P. Nitse, K. Parker, D. Krumwiede and T. Ottaway, “The Impact of Color in the E-Commerce Marketing of Fashions: An Exploratory Study,” European Journal of Marketing, Vol. 38, No. 7, 2004, pp. 898-915. doi:10.1108/03090560410539311

[39] W. R. Swinyard and S. M. Smith, "Why People (Don’t) Shop Online: A Lifestyle Study of the Internet Consumer," Psychology and Marketing, Vol. 20, No. 7, 2003, pp. 567597. doi:10.1002/mar.10087

[40] V. Fuchs, “The Service Economy,” National Bureau of Economic Research, New York, 1968.

[41] U. S. Karmarkar and U. M. Apte, "Operations Management in the Information Economy: Information Products, Processes, and Chains,” Journal of Operations Management, Vol. 25, No. 2, pp. 438-453. doi:10.1016/j.jom.2006.11.001

[42] R. D. Banker and S. M. Datar, C. F. Kemerer, “A Model 
to Evaluate Variables Impacting the Productivity of Software Maintenance Projects," Management Science, Vol. 37, No. 1, 1991, pp. 1-18. doi:10.1287/mnsc.37.1.1

[43] C. X. Liu, H. P. Tian, et al., "Incentive Contract Design in Competing Distribution Channels," Production Planning \& Control, Vol. 20, No. 4, 2009, pp. 295-305. doi:10.1080/09537280902843623

[44] B. Holmstrom and P. Milgrom, "Aggregation and Linearity in the Provision of Intertemporal Incentives,” Econo- metrica, Vol. 55, No. 2, 1987, pp. 303-328. doi:10.2307/1913238

[45] J. J. Laffont, “Applied Incentive Theory,” Peking University Press, Beijing, 2001.

[46] F. Chen, "Salesforce Incentives, Market Information, and Production/Inventory Planning,” Management Science, Vol. 51, No. 1, 2005, pp. 60-75. doi:10.1287/mnsc.1040.0217 